\title{
The Photochemistry on Space Station (PSS) Experiment: Organic Matter under Mars-like Surface UV Radiation Conditions in Low Earth Orbit
}

\author{
Fabien Stalport, ${ }^{1}$ Laura Rouquette, ${ }^{1}$ Olivier Poch, ${ }^{2}$ Tristan Dequaire, ${ }^{1}$ Naïla Chaouche-Mechidal, ${ }^{1}$ Shanèle Payart, \\ Cyril Szopa, ${ }^{3}$ Patrice Coll, ${ }^{1}$ Didier Chaput, ${ }^{4}$ Maguy Jaber, ${ }^{5}$ François Raulin, ${ }^{1}$ and Hervé Cottin ${ }^{1}$
}

\begin{abstract}
The search for organic molecules at the surface of Mars is a top priority of the Mars Science Laboratory (NASA) and ExoMars 2020 (ESA) space missions. Their main goal is to search for past and/or present molecular compounds related to a potential prebiotic chemistry and/or a biological activity on the Red Planet. A key step to interpret their data is to characterize the preservation or the evolution of organic matter in the martian environmental conditions. Several laboratory experiments have been developed especially concerning the influence of ultraviolet (UV) radiation. However, the experimental UV sources do not perfectly reproduce the solar UV radiation reaching the surface of Mars. For this reason, the International Space Station (ISS) can be advantageously used to expose the same samples studied in the laboratory to UV radiation representative of martian conditions. Those laboratory simulations can be completed by experiments in low Earth orbit (LEO) outside the ISS. Our study was part of the Photochemistry on the Space Station experiment on board the EXPOSE-R2 facility that was kept outside the ISS from October 2014 to February 2016. Chrysene, adenine, and glycine, pure or deposited on an iron-rich amorphous mineral phase, were exposed to solar UV. The total duration of exposure to UV radiation is estimated to be in the 1250-1420 h range. Each sample was characterized prior to and after the flight by Fourier transform infrared (FTIR) spectroscopy. These measurements showed that all exposed samples were partially degraded. Their quantum efficiencies of photodecomposition were calculated in the $200-250 \mathrm{~nm}$ wavelength range. They range from $10^{-4}$ to $10^{-6}$ molecules $\cdot$ photon $^{-1}$ for pure organic samples and from $10^{-2}$ to $10^{-5}$ molecules $\cdot$ photon ${ }^{-1}$ for organic samples shielded by the mineral phase. These results highlight that none of the tested organics are stable under LEO solar UV radiation conditions. The presence of an iron-rich mineral phase increases their degradation. Key Words: MarsAstrobiology_Organic matter-Low Earth orbit_UV radiation-EXPOSE. Astrobiology 19, 1037-1052.
\end{abstract}

\section{Introduction}

T HE SEARCH FOR ORGANIC MOLECULES at the surface of Mars started in the 1970s. The in situ Viking exploration mission reached the surface of the planet with instruments devoted to the detection of an extant biological activity and search for organic matter in regolith samples. Chlorohydrocarbons were detected in the samples, but they were considered a terrestrial contamination. No organic matter indigenous to Mars has been unambiguously detected with the Viking instrumentation (Biemann, 1979). At that time, the nondetection of organic molecules was considered surprising, even if it is possible that endogenous organic compounds present on Mars for millions of years are not detectable because of burials or degradation processes. Indeed, the interplanetary medium is still an active exogenous source of organic matter (Botta and Bada, 2002; Botta, 2005; Elsila et al., 2009; Martins and Sephton, 2009; Schmitt-Kopplin

\footnotetext{
${ }^{1}$ Laboratoire Interuniversitaire des Systèmes Atmosphériques (LISA), UMR CNRS 7583, Université Paris Est Créteil et Université de Paris, Institut Pierre Simon Laplace, Créteil, France.

${ }^{2}$ Université Grenoble Alpes, CNRS, CNES, IPAG, Grenoble, France.

${ }^{3}$ Laboratoire Atmosphères, Milieux, Observations Spatiales (LATMOS), UMR CNRS 8190, Université Pierre et Marie Curie, Université Versailles St-Quentin, Paris, France.

${ }_{5}^{4}$ Centre National d'Etudes Spatiales, Toulouse, France.

${ }^{5}$ Sorbonne Université, Laboratoire d'Archéologie Moléculaire et Structurale (LAMS), CNRS UMR 8220, Paris, France.
} 
et al., 2010; Mumma and Charnley, 2011; Dartois et al., 2013; Cochran et al., 2015; Martins, 2019). This exogenous organic matter should have been detected by the Viking instruments. Today this result is explained by these two main hypotheses: (i) the gas chromatograph-mass spectrometer (GCMS) instrument would not have been ideally suited to detect low levels of organics in the samples collected by Viking (Navarro-González et al., 2006, 2010), and (ii) organics were effectively absent from the samples collected because of chemical processes occurring at the surface of the planet, leading to the degradation of these molecules (Stoker and Bullock, 1997; Benner et al., 2000; ten Kate et al., 2006; Stalport et al., 2009, 2010; Pavlov et al., 2012; Poch et al., 2013, 2014, 2015). Since 2012, the search for organic matter at the surface of Mars has had an exciting new start with the Mars Science Laboratory (MSL/NASA) mission and the robotic space rover Curiosity. The rover has a robotic arm with the Sample Acquisition, Processing, and Handling (SA/ $\mathrm{SPaH}$ ) subsystem. This subsystem is responsible for the acquisition of rock and soil samples down to $\sim 10 \mathrm{~cm}$ depth from the martian surface. The Sample Analysis at Mars (SAM) experiment is specifically dedicated to detect and identify organic compounds. Organic matter (chlorohydrocarbons) indigenous to Mars was detected for the first time on samples collected at the Yellowknife Bay area (Freissinet et al., 2015). The detection of chlorohydrocarbons by the SAM instrument led to a new review of the results on the detection of these same molecules during the Viking mission and reopened the debate about the absence of organic matter indigenous to Mars in the analyzed samples, although this remains to be confirmed (Guzman et al., 2018). More recently, aromatic and aliphatic sulfur-bearing compounds were also detected when pyrolyzing above $\sim 600^{\circ} \mathrm{C}$ lacustrine mudstones collected at the base of the $\sim 3.5$-billion-yearold Murray formation at Pahrump Hills (Eigenbrode et al., 2018). The detection of such organics outgassing from the samples at high temperature proves their indigenous origin. However, even if their presence in the soil as they were detected cannot be excluded, these molecules are strongly suspected to originate from reactions of carbonaceous organic matter present in the samples with chlorine and sulfur species present in minerals, such as perchlorates (Hecht et al., 2009; Glavin et al., 2013). Therefore, the chemical precursors of the detected chlorinated or thiophenic compounds remain unknown, and we can only speculate on their structure and origin (biotic? abiotic?). One possible assumption to explain this observation is that a significant fraction of the organics could be altered or degraded by the radiation, oxidation, or related/ synergetic processes at the surface of the planet.

In order to characterize the possible evolution of organic matter at the martian surface, a set of laboratory and low Earth orbit (LEO) experiments are devoted to evaluate the preservation or evolution of organic compounds in simulated martian surface environmental conditions, as the experiments developed within the Mars Organic Molecules Irradiation and Evolution (MOMIE) and EXPOSE programs (Stalport et al., 2008, 2009, 2010; Noblet et al., 2012; Poch et al., 2013, 2014, 2015). The major goals of these studies are (i) the identification of the nature of the organic molecules which could be stable (parent molecules) or metastable (daughter molecules) at the surface of Mars and (ii) the quantification of their abundance at the surface of the planet.
Concerning the LEO experiments, we obtained our first data on the photostability of organic matter under Mars-like UV conditions in 2007 (Stalport et al., 2010). The UVolution experiment was part of the Biopan-6 payload set outside the Foton-M3 Russian automated capsule that, for 12 days in September 2007, orbited Earth at roughly $300 \mathrm{~km}$ altitude. Biopan is an ESA exposure facility that enables a direct exposure of various samples to space conditions (Barbier et al., 2002; Demets et al., 2005). During this experiment, we exposed three carboxylic acids: mellitic, phthalic, and trimesic acids. These compounds were targeted because the surface of Mars is considered to be an oxidative environment, and results of a theoretical study led by Benner et al. (2000) with regard to the chemical pathways from this oxidative environment on organic molecules of interplanetary infall in the martian soil could produce metastable carboxylic acids. We also selected a fourth molecule related to both meteoritic and micrometeoritic material: $\alpha$-aminoisobutyric acid (Brinton et al., 1998; Glavin et al., 2004). Two sets of samples were implemented open exposition cells (Cottin et al., 2008): pure organic molecules were directly deposited by sublimation onto the surface of optical windows, and pure organic molecules were directly deposited by sublimation on a layer of the iron-rich Mars analog soil JSC Mars-1 (Allen et al., 1998); the mineral phase was deposited first by evaporation on the optical windows. Our results showed that the organic targets were photodegraded if directly exposed to filtered solar UV radiation. Moreover, the presence of a martian analog increased the photodestruction rate of the organic molecules. Our second experiment, PROCESS, was part of ESA's EXPOSE-E mission and was installed outside the European Columbus module of the International Space Station (ISS) for 18 months from February 2008 to August 2009 (Rabbow et al., 2012). During this experiment, we studied the stability of two amino acids, glycine and serine, and one carboxylic acid, phtalic acid (Noblet et al., 2012). This time we used closed exposure cells in order to keep and analyze the potential gaseous products after UV exposition. The three organic compounds were deposited as pure homogeneous thin film by sublimation. For phthalic acid, we also prepared samples with JSC Mars-1 (same procedures as the UVolution experiment). The organic compounds were completely photodegraded. Some gaseous molecules were detected, but they could not be securely dissociated from contamination produced by the closed cells themselves, and it was difficult to conclude on their origin.

An inventory of the current Mars surface environmental conditions reveals that several processes could be involved in the evolution of organic matter. The list of these processes is not exhaustive, but we can cite energetic particle irradiation such as ultraviolet (UV), X-ray, protons, electrons (Kuhn and Atreya, 1979; Cockell et al., 2000; Patel et al., 2002; Dartnell et al., 2007; Ehresmann et al., 2017), and/or potential oxidation reaction with oxidative species such as perchlorates and hydrogen peroxide (Lasne et al., 2016). Among these processes, UV radiation can be particularly efficient (Fig. 1). Numerical models predict that the surface of Mars is exposed to an energetic UV flux in the 190-400 nm range (Kuhn and Atreya, 1979; Cockell et al., 2000; Patel et al., 2002). Recently, the UVABC flux in the wavelength range $200-380 \mathrm{~nm}$ was measured directly on the ground by the Rover Environmental Monitoring Station 


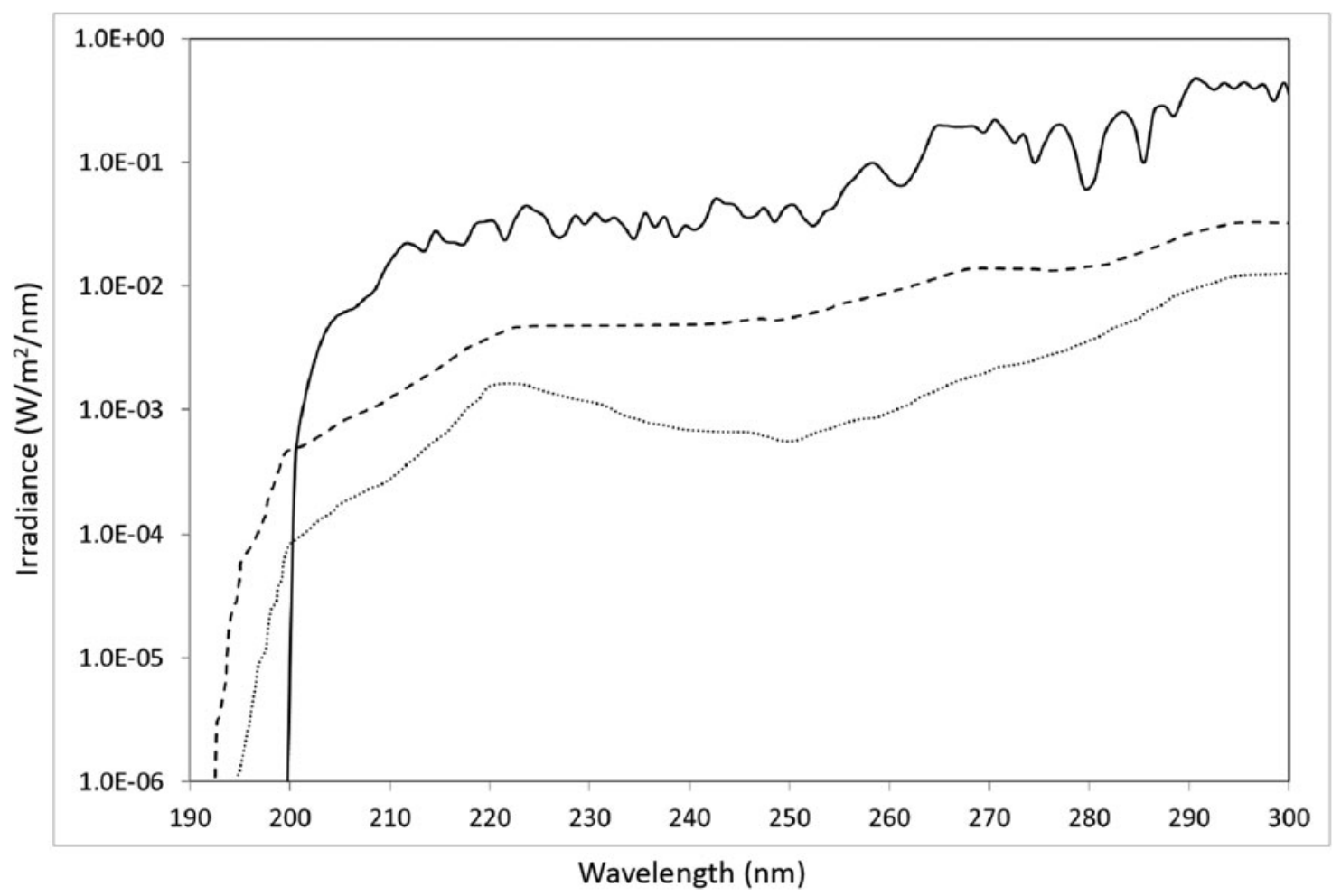

FIG. 1. Absolute average irradiance spectrum received (calculated from LISIRD database and average transmittance of the $\mathrm{MgF}_{2}$ and $\mathrm{KBr}$ windows) at the top of the sample in the PSS experiment (black line) compared with two theoretical irradiance spectra at the surface of Mars for two extreme scenarios: (1) during northern summer for low dust loading $(\tau=0.1)$, at the equator $\left(0^{\circ}\right)$ and local noon (thicker dotted lines) (taken from Patel et al., 2002); (2) during spring (vernal equinox) for a dusty day $(\tau=2.0)$, at $60^{\circ} \mathrm{N}$ and local noon (thinner dotted lines) (taken from Cockell et al., 2000 ).

(REMS) instrument aboard the Curiosity rover (GómezElvira et al., 2014). The authors specify that the flux shows diurnal cycles with a total irradiance varying from 0 at night to $\sim 20 \mathrm{~W} \cdot \mathrm{m}^{-2}$ at midday (according to the atmospheric dust opacity). The calculated irradiance from 200 to $400 \mathrm{~nm}$ is $21 \pm 7 \mathrm{~W} \cdot \mathrm{m}^{-2}$ for the theoretical models depending on the scenario. Therefore, these different values are of the same order. Laboratory experiments have been developed to mimic such radiation conditions and to evaluate their impact on organic materials susceptible to be present at the martian surface (Stoker and Bullock, 1997; Gontareva, 2005; ten Kate et al., 2005, 2006; Stalport et al., 2008, 2009; Shkrob et al., 2010; Poch et al., 2013, 2014, 2015; dos Santos et al., 2016). Those studies highlighted the degradation of most of the organic molecules. Nevertheless, the validity of these studies and their extrapolation to extraterrestrial environments such as Mars can be questioned as long as they have not been confronted with similar experiments conducted in space. For specific conditions, such as the simulation of the surface of Mars, where photons below $190 \mathrm{~nm}$ have been filtered by the atmosphere (Cockell et al., 2000), deuterium discharge or high-pressure xenon UV lamps are able to reproduce quite faithfully the solar emission continuum above $200 \mathrm{~nm}$ (ten Kate et al., 2005; Poch et al., 2013). However, these simulations do not take into account simultaneous UV radiation, temperature variations, the solar wind, and cosmic rays. The laboratory experimental simulations are then advantageously complemented with in situ space experiments in order to evaluate to what extent they reflect the reality of the space environment (Cottin et al., 2017). A good simulation of these parameters is very important in order to estimate the kinetic constants (lifetime, photolysis rate constant, quantum efficiencies) for each organic compound. These kinetic constants are themselves essential to predict the concentration of organic matter on Mars as a function of the depth, latitude, longitude, geological periods. Moreover, they can allow us to propose where to search for the most preserved organics on Mars and which organic compounds and their potential photoproducts could be present. Therefore, we also developed complementary experiments to support laboratory experiments and allow the exposure of samples to the solar spectrum in LEO, as it is almost qualitatively identical to the UV spectrum in the $200-400 \mathrm{~nm}$ range at the surface of Mars (Fig. 1). LEO and laboratory experiments are truly complementary in order to progress in our understanding about the potential photostability of organic matter: (i) LEO experiments are more representative of the radiative environment of the martian surface if the adequate filters are used, but each mission to the ISS is very time consuming, very few samples can be irradiated, and the opportunity for such missions is also limited. (ii) On the other hand, laboratory experiments are much easier to develop, and a lot of samples can be studied; then we can choose which samples are the most relevant to expose in space conditions.

The Photochemistry on the Space Station (PSS) experiment is the topic of this paper: it was part of ESA's EXPOSE-R2 mission, and it was installed outside the Russian module of the ISS for almost 16 months from October 
2014 to February 2016. The EXPOSE-R2 flight hardware consisted of three flight trays with four compartments each. Each of these compartments housed a stack of two or three sample carriers and was closed to the outside environment either by the sample carriers themselves or by top windows and window frames. All trays were previously closed on the ground under inert dinitrogen atmosphere at ambient pressure provided in an anaerobic workbench flooded with dinitrogen. After final integration of all samples in the sample carriers, storage time until upload was limited to 6 months. The EXPOSE-R2 trays were launched successfully the night of July 23, 2014, to the ISS. After successful docking on July 24 , the trays were moved into the ISS. The EXPOSE-R2 experiment was successfully mounted outside the ISS on August 18, 2014. August 20, 2014, marked the start of the exposure period of the experiment, but the samples were still in the dark protected from solar UV radiation by a cover. After a dark evacuation period of 63 days in order to avoid any contamination of a residual atmosphere (both terrestrial and of ISS origin), the cover on top of the EXPOSE-R2 trays was removed, marking the start of the UV exposure time on October 22, 2014. Flight data from the ISS were received regularly that were used to model solar irradiation of EXPOSE-R2 by RedShift and to check the temperature of the samples. UV fluences for each sample were calculated and respective fluences for Mission Ground Reference (MGR) irradiation on ground provided every 2 months for each compartment by RedShift (more details in the "test parameters" section). These data were used by RedShift to validate the calculated shadowing maps of EXPOSE samples. On February 3, 2016, the EXPOSE-R2 trays were returned into the ISS. Before return to the ground on March 2, 2016, EXPOSE-R2 was stored in the ISS for another 28 days. After ground inspections of the trays in an anaerobic workbench, the samples were delivered to our laboratory March 14, 2016.

\subsection{Test parameters}

Several molecules of interest in the context of the search for organics on Mars have been studied in both the MOMIE simulation setup (Poch et al., 2013, 2014, 2015) and LEO experiment under Mars-like surface UV radiation conditions. These molecular targets include a polycyclic aromatic hydrocarbon, chrysene; a purine nucleobase, adenine; and an amino acid, glycine. Some of the samples were pure organic deposit (adenine, chrysene) or mixed in the presence of an iron-rich amorphous mineral phase (glycine, adenine). The PSS experiment was part of the science payload of the European EXPOSE-R2 exposure facility, which was attached outside the Zvezda Russian module of the ISS.

\section{Materials and Methods}

\subsection{Test molecules}

The targeted organic molecules were selected based on two criteria: representativity of endogenous and/or exogenous sources of molecules, and potential resistance to the current environmental conditions at the surface of Mars. In addition, we chose to select molecules with different chemical structures and functional groups so that the set of simulations performed gives a broad picture of organic matter evolution at the surface of Mars. From these criteria, the molecules studied are as follows: (i) Chrysene $\left(\mathrm{C}_{18} \mathrm{H}_{12}\right)$, a polycyclic aromatic hydrocarbon (PAH), because of the ubiquity and abundance of these molecules in space (Naraoka et al., 2000) and their consecutive delivery via exogenous sources on Mars, along with potential endogenous sources (Zolotov and Shock, 1999; Steele et al., 2012). Chrysene was selected because it is one of the most abundant among the PAHs detected in carbonaceous chondrites and micrometeorites (Clemett et al., 1998). (ii) Adenine $\left(\mathrm{C}_{5} \mathrm{H}_{5} \mathrm{~N}_{5}\right)$, a purine nucleobase, because of its likelihood of synthesis at and/or delivery to the martian surface (Hayatsu et al., 1975; Roy et al., 2007; Callahan et al., 2011). Moreover, nucleobases and particularly adenine are known to exhibit photostability over a wide range of UV excitation energies (Perun et al., 2005; Barbatti and Ullrich, 2011). Finally, adenine is a molecule found in DNA and RNA. This molecule is related to life as we know it and probably to prebiotic chemistry. (iii) Glycine $\left(\mathrm{C}_{2} \mathrm{H}_{5} \mathrm{NO}_{2}\right)$, the simplest amino acid, is one of the most abundant amino acids detected in meteorites and comets (Botta and Bada, 2002; Martins et al., 2007, 2015; Elsila et al., 2009; Altwegg et al., 2016), and its evolution under simulated martian conditions has already been studied in several laboratories (ten Kate et al., 2005, 2006; Stalport et al., 2008; Poch et al., 2013) and LEO experiments (Stalport et al., 2010; Noblet et al., 2012).

We also studied the influence of an iron-rich amorphous mineral phase (JSC Mars-1) similar to the martian dust on some of our samples in LEO (Rieder et al., 1997; Allen et al., 1998). JSC Mars-1 is a martian regolith simulant specifically developed to support scientific research and engineering studies. The simulant is the $<1 \mathrm{~mm}$ fraction of weathered volcanic ash from Pu'u Nene, a cinder cone on the Island of Hawaii and has been characterized by several analytical techniques. Because the martian dust is spread all over the surface of Mars and mostly composed of iron in the form of iron oxides, we wanted to estimate its impact on organic matter, particularly from the interplanetary medium. The molecules from this source could be more easily in contact with the martian dust when meteorites are eroded over time. We have also performed several laboratory experiments with iron-rich mineral phase (nontronite, Femontmorillonite, JSC Mars-1; see Poch et al., 2015, for example), and we have planned to compare both LEO and laboratory data in order to better define the kinetic parameters we need to evaluate the concentration of organics on Mars. Our goal is to determine more precisely the quantum efficiency of photodecomposition values of our molecules, as we can expect from our data a degradation of organic matter in the presence of iron-rich mineral phase. A laboratory study of the impact of minerals containing ferrous iron also showed that they preserved the lowest amount of organic compounds (amino acids) (dos Santos et al., 2016).

\subsection{Flight experiment hardware}

For the samples of the PSS experiment related to Mars, we used closed exposure cells in order to keep the gaseous phase potentially produced by the photolysis of the organic compounds (12 mm diameter, $9.1 \mathrm{~mm}$ high) (Fig. 2). Each cell was composed of two aluminum cylinders, a top and a bottom one, and $\mathrm{MgF}_{2}$ windows ( $1 \mathrm{~mm}$ thickness, $8.8 \mathrm{~mm}$ 
FIG. 2. "Mars" closed cells fitting on the facility of EXPOSE. This type of cell was developed specifically for the PSS experiment. It allows depositing a sample selected for martian studies under a filter $(\mathrm{KBr})$ that simulates the transmission of UV (200$400 \mathrm{~nm}$ ) radiation in the martian atmosphere. Since $\mathrm{KBr}$ is very hygroscopic, it is placed inside the closed cell as described. Pure organic deposits were made directly on the $\mathrm{KBr}$ filter. Combinations of organic/ironrich phase deposits were made on a $\mathrm{MgF}_{2}$ window. In this last configuration, $\mathrm{KBr}$ is only a filter.
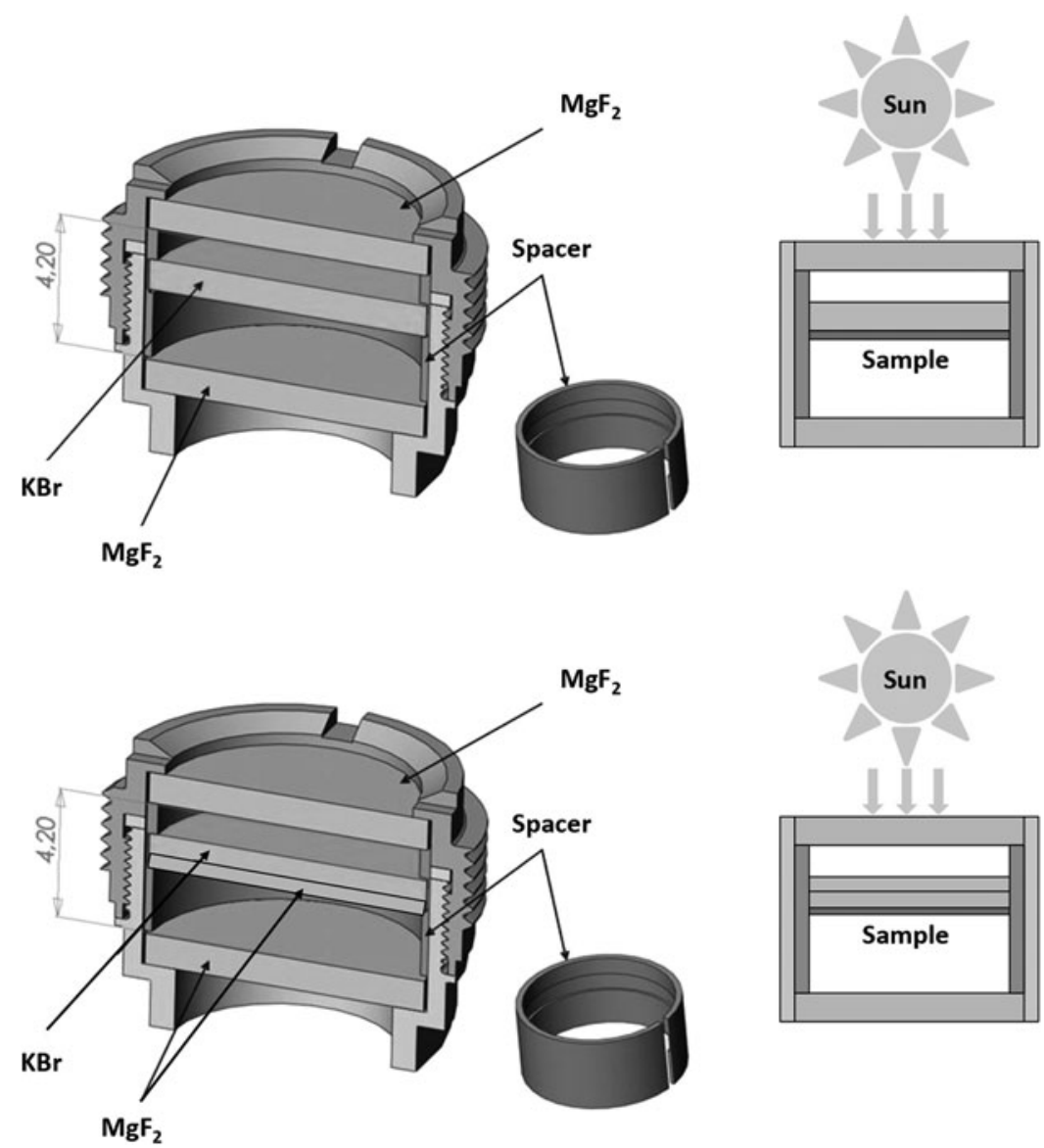

diameter) brazed on both sides. Inside the cell, a spacer maintained the sample on a $\mathrm{KBr}$ window (1 mm thickness, $8.8 \mathrm{~mm}$ diameter) for pure organic deposits or on a $\mathrm{MgF}_{2}$ window $(0.5 \mathrm{~mm}$ thickness, $8.8 \mathrm{~mm}$ diameter $)$ for the ironrich phase/organic mixture deposit. For this last configuration, we also added a $\mathrm{KBr}$ window $(0.5 \mathrm{~mm}$ thickness, $8.8 \mathrm{~mm}$ diameter) to filter UV radiation below $200 \mathrm{~nm}$. After the spacer was loaded with the sample, the two cylinders were screwed together under an argon atmosphere (1.5 bar). In order to minimize leaks of the closed exposure cell, it was sealed with a Viton O-ring and laser welding (Air Liquide, Grenoble) of the two parts. The $\mathrm{KBr}$ windows were chosen because this material is transparent in the $200-400 \mathrm{~nm}$ wavelength range, and it efficiently absorbs photons below $200 \mathrm{~nm}$. The spectrum of the UV photons transmitted throughout such a window is close to that reaching the surface of Mars (190-400 nm wavelength range) (Kuhn and Atreya, 1979; Cockell et al., 2000; Patel et al., 2002). On the EXPOSE-R2 facility, each cell exposed to solar $\mathrm{UV}$ radiation is associated to an identical cell placed right below and protected from the UV light. It is used as a flight dark control (Fig. 3). We also added empty cells as blanks in order to estimate the potential degradation of the optical windows under space conditions.

After the return of the cells to our laboratory in March 2016, the $\mathrm{MgF}_{2}$ windows exposed to solar UV radiation showed multiple scratches and cracks. Unfortunately, the pressure inside those cells dropped significantly, and we assumed that the potential gaseous photoproducts were lost in space. We performed gas chromatography coupled to mass spectrometry analyses but, as expected, no new compounds were detected, probably because the gaseous compounds leaked out from the cell. Therefore, we will not discuss analyses and results concerning the gas phase inside our cells in this article

\subsection{Loading of the exposure cells}

The studied organic molecules (Table 1) consist of nanometer-thin (300-400 $\mathrm{nm}$ for adenine, 600-1000 $\mathrm{nm}$ for chrysene, $5500-6500 \mathrm{~nm}$ for glycine) organic deposits. The deposits were prepared by heating the commercial powders of these molecules under secondary vacuum $\left(\sim 10^{-5} \mathrm{mbar}\right)$, which causes the molecules to sublimate and then recondense on a $\mathrm{MgF}_{2}$ or $\mathrm{KBr}$ window. For this purpose, we used the vacuum sublimation chamber described in Guan et al. (2010). The deposits of pure organic molecules (adenine or chrysene) were produced as homogeneous thin films directly on the $\mathrm{KBr}$ window. The films were several hundred nanometers thick as measured by interferometry as described in Cottin et al. (2012).

For the organic/iron-rich phase samples, a stepwise approach was used. First a mineral film was deposited on the $\mathrm{MgF}_{2}$ window ( $0.5 \mathrm{~mm}$ thickness, $8.8 \mathrm{~mm}$ diameter) as follows: iron-rich martian simulant was sieved, and the $<20 \mu \mathrm{m}$ fraction was collected and dispersed in ethanol; the suspension was deposited on the $\mathrm{MgF}_{2}$ window and then heated to $50^{\circ} \mathrm{C}$ to evaporate the solvent. A Teflon ring around the $\mathrm{MgF}_{2}$ 


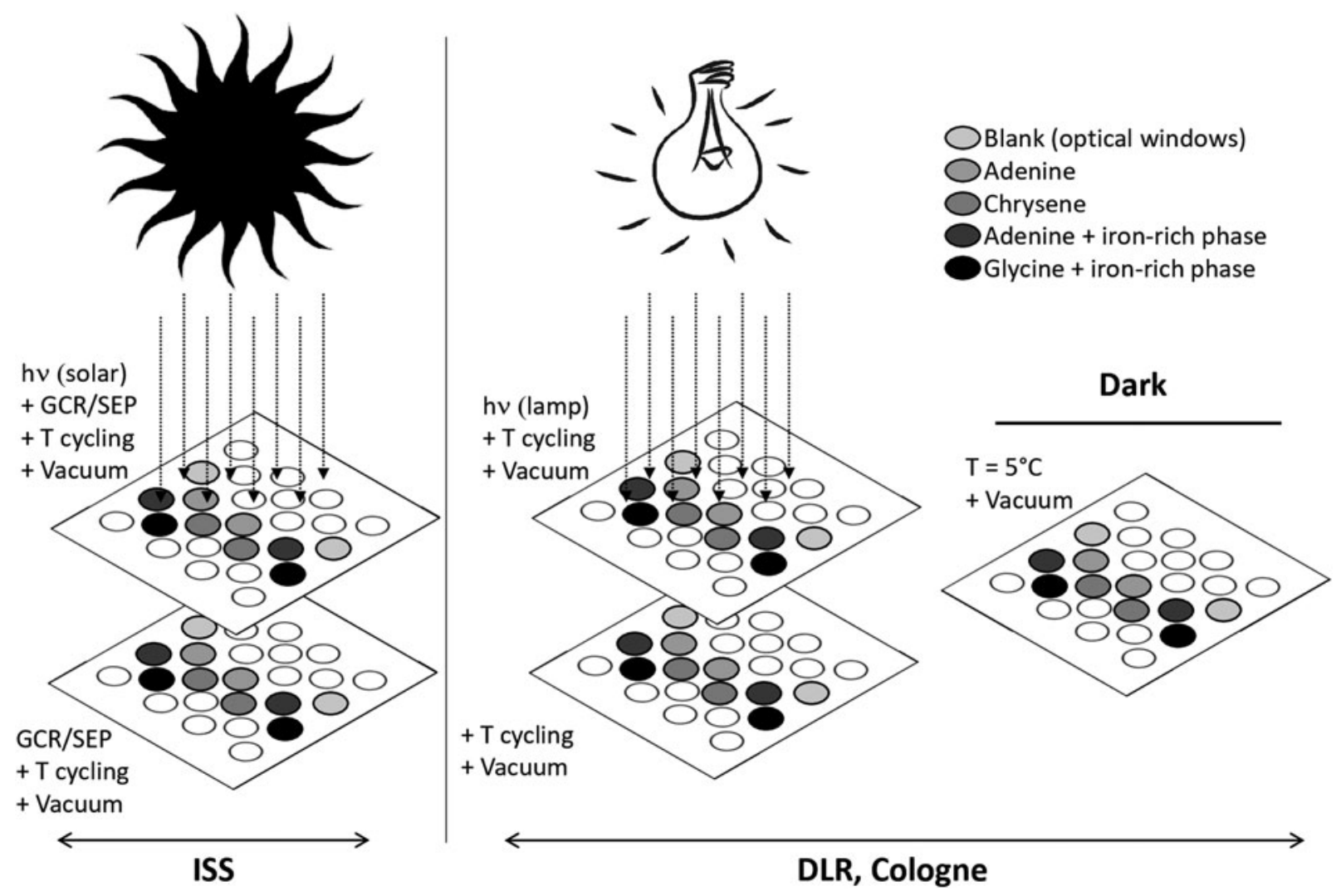

FIG. 3. Principle of exposure of samples during PSS experiments. Two layers of samples are installed in orbit outside the ISS (left). Only the upper layer is exposed to UV radiation; the bottom one is a dark control (no UV radiation). Two layers are exposed to solar simulator $(\lambda>190 \mathrm{~nm})$ in a vacuum chamber at Cologne DLR (middle) that also reproduces temperature variations measured in orbit. A last layer is kept at DLR, under vacuum, at constant temperature (right). The difference between the evolutions of the different layers of samples makes it possible to distinguish the contributions of the UV radiation and galactic cosmic ray (GCR) in the space environment from the Sun or cosmic radiation, and the temperature.

Table 1. Thickness, Half-Life (Extrapolated to the Average Martian UV Flux), and Quantum EfFiciency of Adenine, Chrysene, and Glycine Determined From MOMIE and PSS Experiments FOR THE SAME UV RADIATION RANGE (200-250 NM)

\begin{tabular}{|c|c|c|c|}
\hline Molecule & Sample & $\begin{array}{l}\text { Sample } \\
\text { thickness }(\mathrm{nm})\end{array}$ & $\begin{array}{l}\text { Quantum efficiency of photodecomposition } \\
200-250 \mathrm{~nm}\left(\text { molecules } \cdot \text { photon }^{-1}\right)\end{array}$ \\
\hline \multirow[t]{3}{*}{ Glycine } & Poch et al., 2014 & $295 \pm 19$ & $6.2 \pm 5.0 \times 10^{-3}$ \\
\hline & Poch et al., 2014 & $322 \pm 80$ & $7.1 \pm 6.2 \times 10^{-3}$ \\
\hline & Poch et al., 2014 & $499 \pm 80$ & $6.0 \pm 4.9 \times 10^{-3}$ \\
\hline \multirow[t]{4}{*}{ Glycine + iron-rich phase } & DLR UV7 & $5415 \pm 1353$ & $3.9 \pm 1.6 \times 10^{-3}$ \\
\hline & DLR UV8 & $6377 \pm 1594$ & $4.1 \pm 1.6 \times 10^{-3}$ \\
\hline & FUV7 & $5463 \pm 1365$ & $8.4 \pm 3.5 \times 10^{-3}$ \\
\hline & FUV8 & $5625 \pm 1406$ & $7.6 \pm 3.4 \times 10^{-3}$ \\
\hline \multirow[t]{6}{*}{ Adenine } & Poch et al., 2014 & $70 \pm 32$ & $1.1 \pm 1.0 \times 10^{-4}$ \\
\hline & Poch et al., 2014 & $100 \pm 3$ & $1.1 \pm 0.9 \times 10^{-4}$ \\
\hline & DLR UV1 & $403 \pm 22$ & $1.3 \pm 0.3 \times 10^{-5}$ \\
\hline & DLR UV2 & $387 \pm 21$ & $1.1 \pm 0.2 \times 10^{-5}$ \\
\hline & FUV1 & $393 \pm 21$ & $1.8 \pm 0.4 \times 10^{-5}$ \\
\hline & FUV2 & $403 \pm 22$ & $2.5 \pm 0.5 \times 10^{-5}$ \\
\hline \multirow[t]{4}{*}{ Adenine + iron-rich phase } & DLR UV5 & $316 \pm 17$ & $3.0 \pm 0.7 \times 10^{-5}$ \\
\hline & DLR UV6 & $326 \pm 18$ & $4.6 \pm 1.0 \times 10^{-5}$ \\
\hline & FUV5 & $344 \pm 19$ & $9.8 \pm 2.3 \times 10^{-5}$ \\
\hline & FUV6 & $350 \pm 19$ & $9.9 \pm 2.2 \times 10^{-5}$ \\
\hline \multirow[t]{5}{*}{ Chrysene } & Poch et al., 2014 & $35 \pm 7$ & $4.9 \pm 4.1 \times 10^{-5}$ \\
\hline & DLR UV3 & $630 \pm 101$ & $0.5 \pm 0.2 \times 10^{-5}$ \\
\hline & DLR UV4 & $617 \pm 99$ & $0.3 \pm 0.1 \times 10^{-5}$ \\
\hline & FUV3 & $1003 \pm 160$ & $1.6 \pm 0.5 \times 10^{-5}$ \\
\hline & FUV4 & $886 \pm 142$ & $2.9 \pm 0.9 \times 10^{-5}$ \\
\hline
\end{tabular}


window kept the iron-rich phase and ethanol in the center of the window during the evaporation of the solvent. The ironrich martian simulant film was $6.1 \pm 1.5 \mu \mathrm{m}$ thick as measured by interferometry. The organic film (adenine or glycine) was then deposited on the surface of the mineral phase using the sublimation chamber as described below (Guan et al., 2010). For each pure organic deposit or organic/iron-rich phase combination, ten samples (i.e., ten cells) were produced.

Based on our laboratory data already obtained (Poch et al., 2014) and previous LEO experiments (Noblet et al., 2012), we anticipated the minimum thickness of our organic deposit in order to avoid the total photodegradation of our deposits after 2 years spent in space (as previously happened during the PROCESS experiment of ESA's EXPOSE-E mission; more detail in Noblet et al. [2012]). Therefore, the organic deposits are sufficiently thicker than in our laboratory experiments.

\subsection{Test parameters}

The 10 samples were split into five pairs as described in Figure 3.

(i) Two "flight sun-exposed" samples that were located in the upper sample carrier of the flight experiment. They were exposed to solar radiation from October 22, 2014, to February 3, 2016, that is, 469 days. The top of the cell samples, on the outer faces of the windows, received a UV radiation flux of $6.39 \pm 0.05 \mathrm{~W} \cdot \mathrm{m}^{-2}$ in the $200-280 \mathrm{~nm}$ wavelength range. This UV flux was calculated from the LISIRD and is an average value from 17 solar UV spectra (one by month) from the Lasp Interactive Solar Irradiance Datacenter (http:// lasp.colorado.edu/lisird/data/sorce_ssi_13). From the perspective of the actual samples, inside the cells, and below the successive windows $\left(\mathrm{MgF}_{2}\right.$ and $\left.\mathrm{KBr}\right)$, the total duration of irradiation during the 16 months in space for each sample ranges from 1250 to $1410 \mathrm{~h}$, depending mainly on the UV transmission of the $\mathrm{KBr}$ and $\mathrm{MgF}_{2}$ windows and the position of the sample on the EXPOSE-R2 facility (data provided from the EXPOSE-R2 simulated solar irradiation from Redshift, Belgium [Redshift, private communication]). These samples also experienced temperature fluctuations between $-12^{\circ} \mathrm{C}$ and $+58^{\circ} \mathrm{C}$ (Rabbow et al., 2017). They are also exposed to solar energetic particles (SEP) or even galactic cosmic rays (GCR) such as electrons, neutrons, protons, $\mathrm{X}$-rays, and gamma rays.

(ii) Two "flight dark control" samples that were located in the lower sample carrier of the flight experiment. These samples experienced the same space environmental conditions and temperature variations as the flight Sun-exposed ones (temperature, for example) but no solar UV radiation. Any degradation of these samples would estimate the impact alone of SEP or GCR on organic matter in comparison with the ground controls.

(iii) Two "ground UV-exposed" samples that were kept in the MGR experiment at the premises of the German Aerospace Center (DLR) in Cologne by the Microgravity User Support Center (MUSC) with a hardware identical to the flight one and a complete flight identical set of samples, under ambient pressure and submitted to a SOL 2000 solar simulator (UV radiation range 200-400 nm [Rabbow et al., 2017]) and thermal cycles, which reproduced the recorded flight temperature. These samples received a UV radiation flux of $183 \mathrm{~W} \cdot \mathrm{m}^{-2}$ in the $200-280 \mathrm{~nm}$ wavelength range. Based on the telemetric data from the EXPOSER2 facility, duration of irradiation was calculated by RedShift as average for each compartment and represents $270.17 \mathrm{~h}$ for our "ground UV-exposed" samples.

(iv) Two "ground thermal cycling" samples that were kept in the MGR experiment at the premises of DLR in Cologne by MUSC with a flight-identical hardware and a complete flight-identical set of samples, under ambient pressure and submitted to thermal cycles, which reproduced the recorded flight temperature. These "ground thermal cycling" samples were not exposed to UV radiation and are the dark control of the "ground UV-exposed" samples.

(v) Two "ground, constant temperature" samples that were kept under vacuum. They were integrated into a special small device, and evacuation was started immediately to a final pressure of $9 \times 10^{-5} \mathrm{~Pa}$ to avoid exposure to air. The evacuated device was equilibrated to $5^{\circ} \mathrm{C}$ constant temperature at the DLR facilities for the entire duration of the mission.

\subsection{PSS sample analyses}

The samples were analyzed before and after the mission by the following:

(i) UV spectroscopy (Perkin-Elmer Instruments "Lambda 40 " UV-Vis spectrometer) providing information on the evolution of the absorption of the sample in the 190-300 nm range by direct transmission through the $\mathrm{MgF}_{2}$ or $\mathrm{KBr}$ window depending on the sample (pure organic or organic/iron-rich phase deposit). Each organic molecule absorbs photons in the $200-280 \mathrm{~nm}$ range. These analyses allow determining if the samples are optically thin samples (meaning UV transmission is $>90 \%$ and then almost all the molecules are irradiated at the same time).

(ii) Fourier transform infrared (FTIR) spectroscopy (Brucker spectrometer, resolution $4 \mathrm{~cm}^{-1}, 8$ scans, spectral domain $4000-800 \mathrm{~cm}^{-1}$ ) by direct transmission through the $\mathrm{MgF}_{2}$ or $\mathrm{KBr}$ window depending on the sample (pure organic or organic/iron-rich phase deposit). The areas of the infrared (IR) spectral features peaks before and after the mission were compared to measure the photolysis efficiency. As only the two spectra measured prior to and after the missions are compared, we also performed laboratory experiments (MOMIE experiment described below) in order to estimate the kinetic evolution of our PSS samples as a function of the duration of irradiation.

\subsection{Mars Organic Molecules Irradiation and Evolution facility}

To study in parallel the kinetics of evolution of organics under simulated martian conditions, a Mars simulation setup called the MOMIE facility was developed as described in detail in Poch et al. (2013) to reproduce mainly the UV radiation and temperature at the martian surface. The same 
pure organic samples as the PSS experiment were placed inside the reactor of the MOMIE simulation setup (see Figs. 1 and 2 in Poch et al. [2013]) where it can be irradiated using a Xenon arc lamp, and monitored in situ by FTIR spectroscopy. For MOMIE experiments, we used only $\mathrm{MgF}_{2}$ windows for our deposits.

The whole MOMIE setup is placed in a glove compartment which is purged and over-pressurized with $\mathrm{N}_{2}$ ( $\geq 99.995 \mathrm{vol} \%$ purity from Linde) to prevent the formation of ozone and water ice. For all the duration of an experiment the reactor is thermostated at $218 \pm 2 \mathrm{~K}$ using a cryothermostated fluid circulation. It is connected to a pumping system maintaining a pressure of $6 \pm 1$ mbar of $\mathrm{N}_{2}$. Since a former study by ten Kate et al. (2006) did not show any impact of a representative Mars atmosphere of carbon dioxide (main compound of the martian atmosphere) on the evolution of glycine samples under UV, compared with a purely $\mathrm{N}_{2}$ atmosphere, we chose to perform our simulation in 6 mbar of $\mathrm{N}_{2}$. The lamp delivers a UV spectrum (190-400 nm) similar to the martian surface radiation spectrum as modeled by Patel et al. (2002), but with a higher flux (Fig. 4). Infrared spectra of the sample acquired in situ throughout the simulation allow us to quantify the decay of the irradiated molecules but also to detect potential solid photoproducts formed during the simulation. Spectra are acquired using a FTIR spectrometer (Spectrum 100 from Perkin Elmer) with 50, 100, or 200 scans depending on the molecule, and at a resolution of $2 \mathrm{~cm}^{-1}$. Ratios $I / I_{\text {ref }}$ are calculated with reference spectra $\left(I_{\text {ref }}\right)$ obtained under the same experimental conditions with a clean $\mathrm{MgF}_{2}$ sample window.
Additionally, UV transmission spectra recorded ex situ before and after simulation using a Perkin-Elmer Instruments "Lambda 40" UV-Vis spectrometer provide also the same information on the evolution of the absorption of the sample in the $190-300 \mathrm{~nm}$ range.

\subsection{Kinetic parameters of the samples}

The goal of the quantitative analysis, using the measured FTIR spectra $I / I_{\text {ref }}$, is the measurement and comparison of the photolysis rate $J$ ([time $]^{-1}$ ) and half-life $t_{1 / 2}$ ([time]) of the studied molecules extrapolated to the surface of Mars conditions. For absorption bands specific to the studied compound, we assume that the number of molecules is proportional to their area $A_{t}\left(\right.$ absorbance $\left.\cdot \mathrm{cm}^{-1}\right)$ based on our experiments (Poch et al., 2014), with $t$ being the irradiation duration. The quantitative evolution of our sample is followed by plotting the relative abundance (calculated as $A_{t} /$ $A_{0}$ ) of the studied compound as a function of the irradiation duration $t$. Assuming that the photodestruction of the molecule $(M)$ is an irreversible process, we have

$$
M+h v=\text { products }
$$

The measurement of $J$ and $t_{1 / 2}$ based on a first-order kinetics only makes sense for optically thin samples (meaning UV transmission is $>90 \%$ and then almost all the molecules are irradiated under the same flux conditions) for which the relative abundance of molecules follows an exponential decay during the irradiation. The PSS samples were as thin

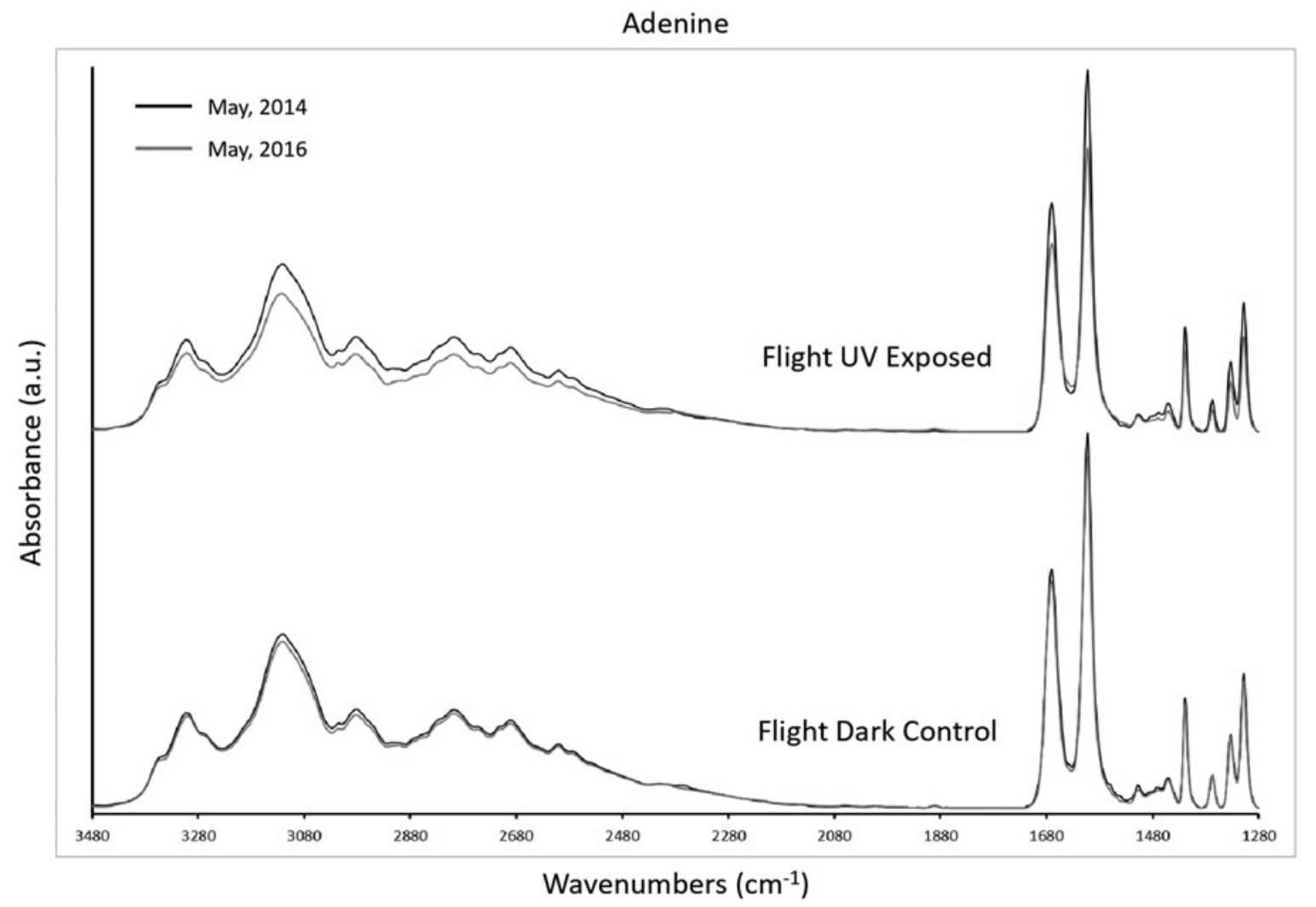

FIG. 4. IR spectra (in the $3480-1280 \mathrm{~cm}^{-1}$ wavelength range with a $4 \mathrm{~cm}^{-1}$ resolution) of a "flight sun-exposed" sample of adenine + iron-rich phase before (black) and after (gray) compared to a "flight dark control". (a.u.= arbitrary units). 
as possible, but the deposits were sufficiently thick in order to prevent the total photodegradation of our samples during the mission. The deposits cannot be fully considered as optically thin; because they are not (based on the experimental UV spectra of the samples) and in order to also get rid of the potential influence of the sample thickness, and to compare PSS and laboratory data, we have subsequently calculated the quantum efficiency of photodecomposition $\phi$ $\left(\right.$ molecules $\cdot$ photon $^{-1}$ ) between 200 and $250 \mathrm{~nm}$ wavelength. $\phi$ is the probability for a molecule to dissociate after the absorption of a photon. We approach the theoretical values of $\phi$ by measuring $\phi_{\exp }$ (experimental quantum efficiency of photodecomposition), the ratio of the number of molecules photodissociated to the number of photons from 200 to $250 \mathrm{~nm}$ wavelengths reaching the molecular deposit during its irradiation, following this equation:

$$
\phi_{\exp }=\frac{N_{\text {degraded }}}{N_{\text {photons }}}
$$

with $N_{\text {degraded }}$ the number of photodegraded molecules during a duration of exposure $t$, determined from the difference between the initial thickness of a deposit (measured by interferometry), and the ratio $A_{t} / A_{0}$ corresponding with the loss of molecules in the sample, the diameter of the deposit, the density and molar mass of the molecule, and with $N_{\text {photons }}$ the number of photons reaching the sample during the duration of exposure $t$, determined from the solar UV flux $(200-250 \mathrm{~nm})$, the energy deposit (Redshift), the total duration of exposure, and the UV transmission of the optical windows.

\section{Results}

The data concerning the MOMIE and previous LEO experiments have been published (Stalport et al., 2010; Noblet et al., 2012; Poch et al., 2013, 2014, 2015), and we will not discuss them in detail. Here we will directly compare and discuss the results of our previous laboratory experiments (Poch et al., 2014, 2015) to the PSS data of the exposed samples.

DLR ground data experiments were performed in ambient atmosphere by mistake, and part of the UV radiation from the UV source was absorbed by the molecules in this atmosphere and in particular the ozone produced from the UV radiation itself. In addition, an organic contamination formed a deposit on the surface of all the optical windows of the DLR ground UVexposed samples which also contributed to an underestimation of the UV flow reaching the samples. The main consequence of these two parameters is that the quantum efficiency of photodecomposition values of the DLR samples are always about a factor of 2 (adenine, adenine + iron-rich phase, glycine + ironrich phase) or 6 (chrysene) lower than those from the PSS flight sun-exposed samples. The quantum efficiency of the DLR ground UV-exposed samples exposed to the UV source could be only considered as a lower limit in the ground experiments.

FTIR spectra of the different PSS flight samples were recorded before the flight on May 2014 and then after the mission on May 2016. In Figure 4 (adenine), Figure 5 (adenine + ironrich martian simulant), Figure 6 (chrysene), and Figure 7 (glycine + iron-rich martian simulant), the IR spectra of the "flight sun-exposed" samples are presented before and after flight. After almost 2 years in space, all the spectral features ("sun-exposed" and "dark") of the initial samples decreased.

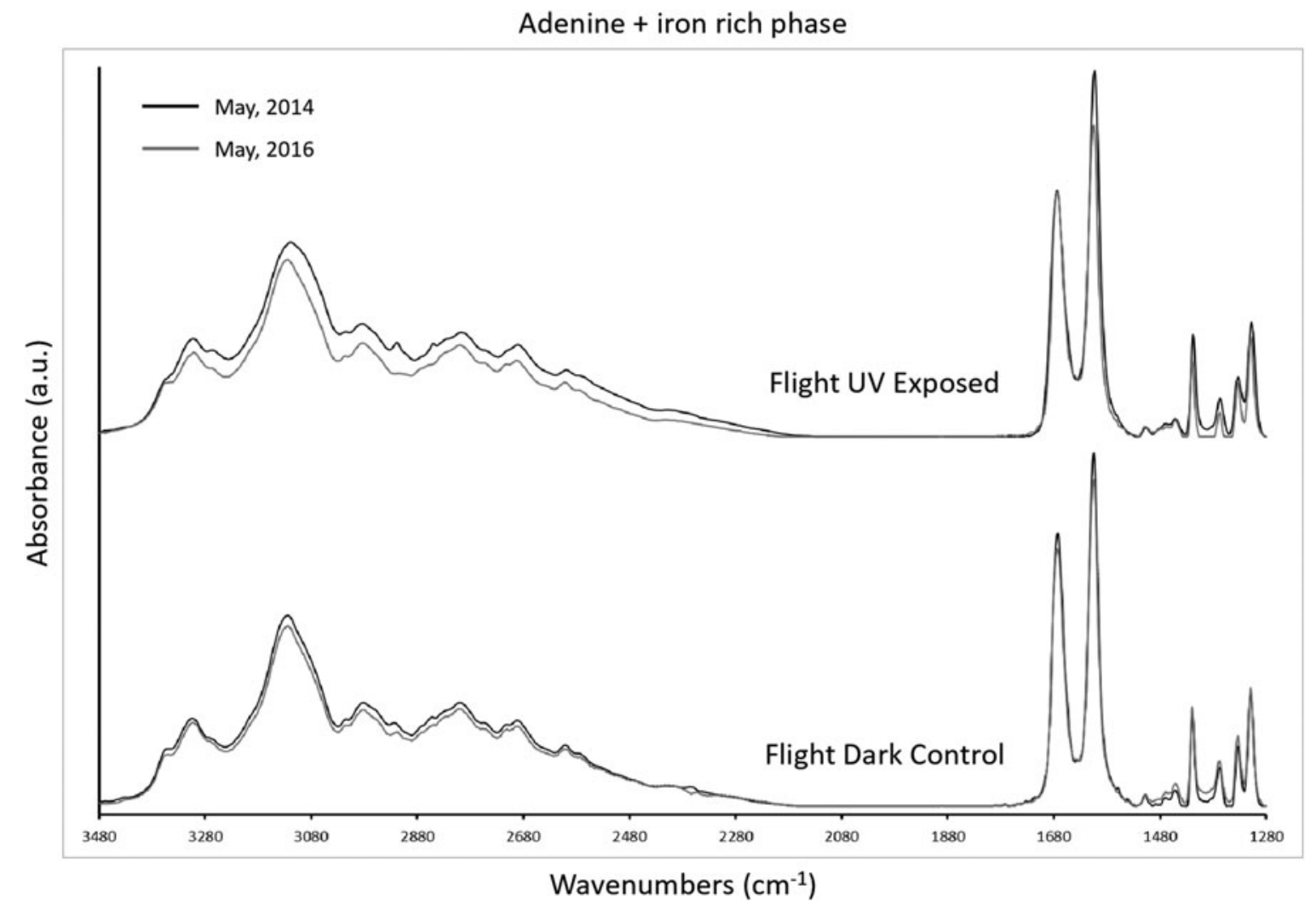

FIG. 5. IR spectra (in the $3480-1280 \mathrm{~cm}^{-1}$ wavelength range with a $4 \mathrm{~cm}^{-1}$ resolution) of a "flight sun-exposed" sample of adenine + iron-rich phase before (black) and after (gray) compared to a "flight dark control". (a.u.= arbitrary units). 


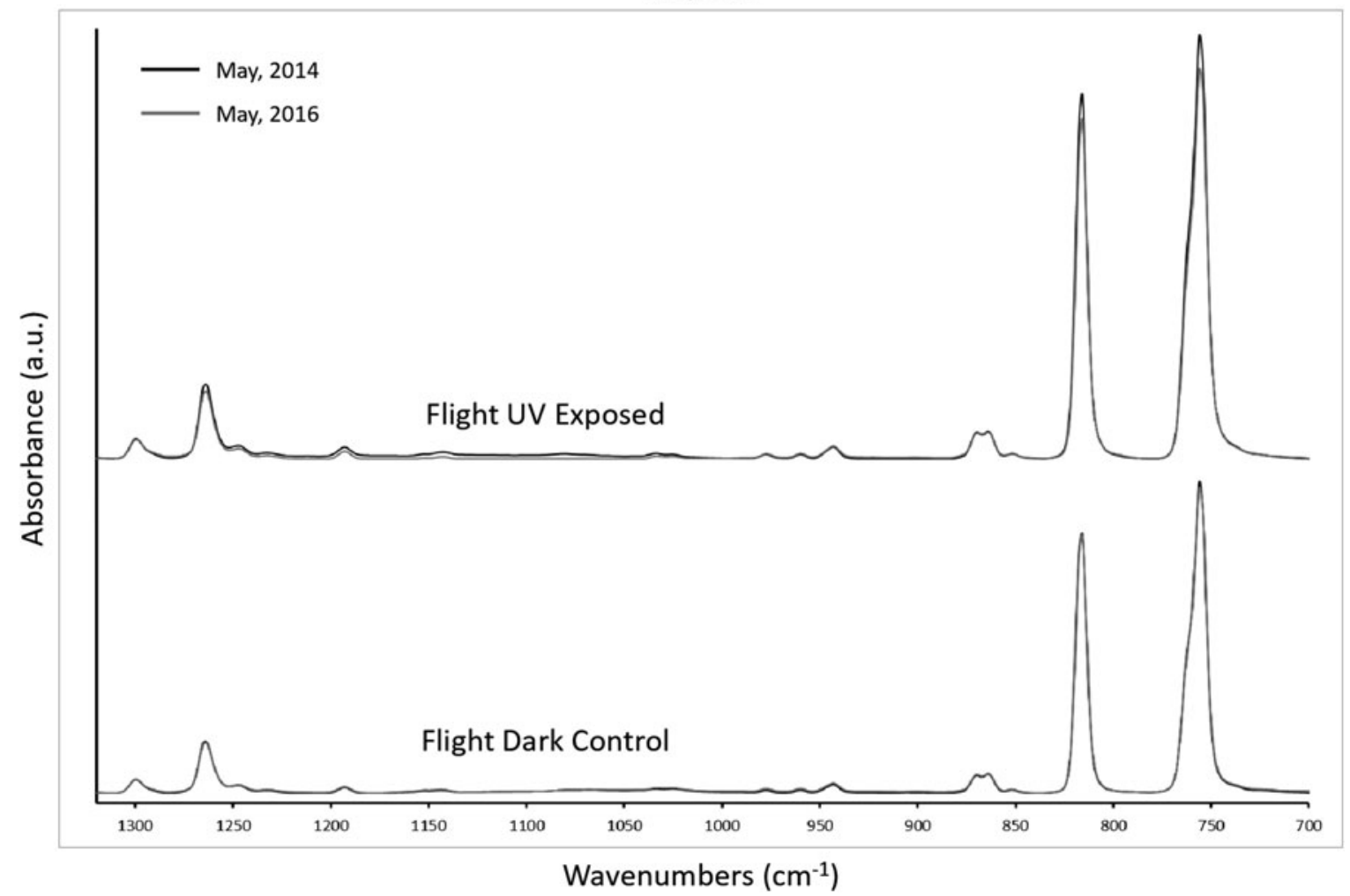

FIG. 6. IR spectra (in the $1320-700 \mathrm{~cm}^{-1}$ wavelength range with a $4 \mathrm{~cm}^{-1}$ resolution) of a "flight sun-exposed" sample of chrysene before (black) and after (gray) compared to a "flight dark control". (a.u. =arbitrary units).

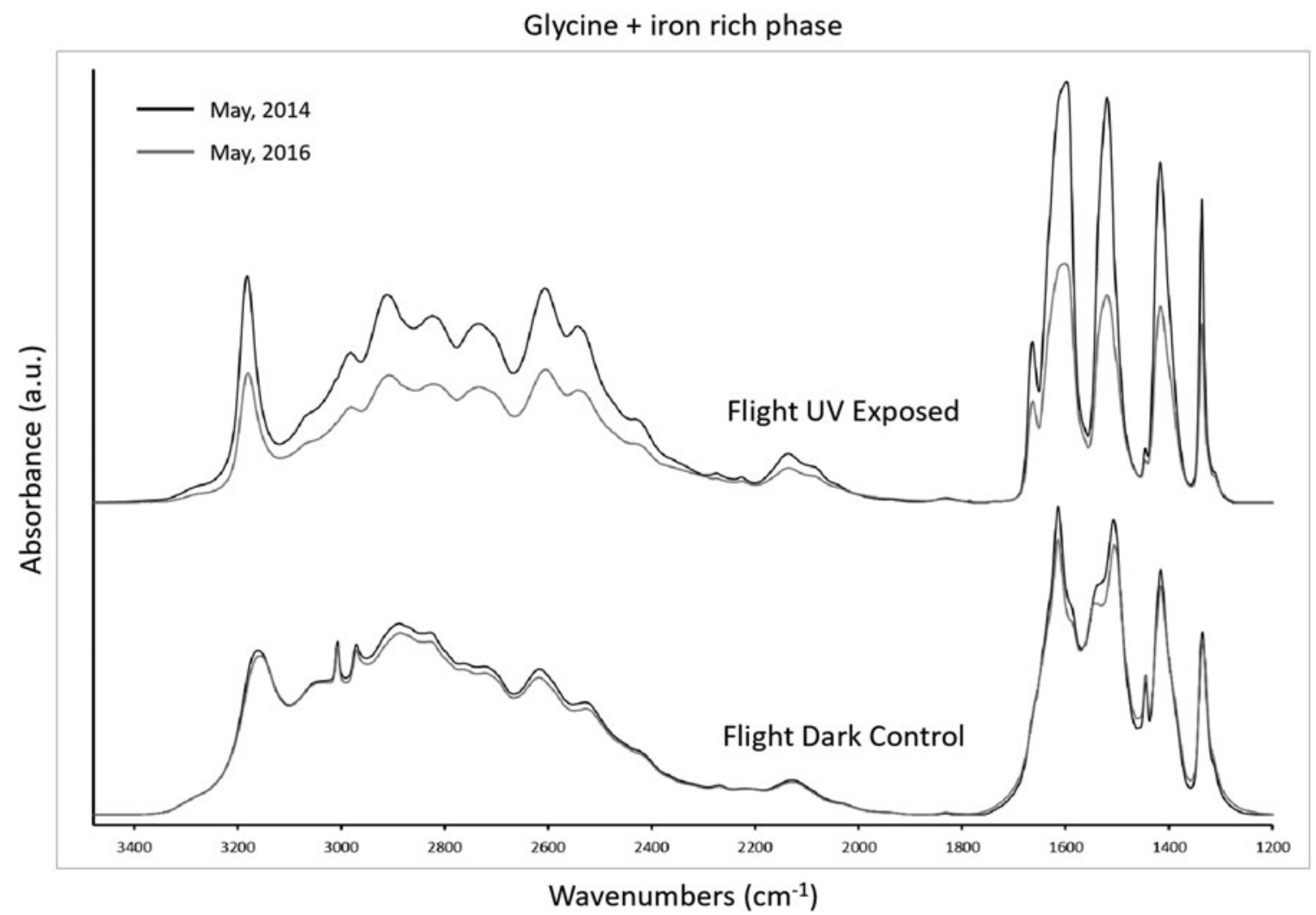

FIG. 7. IR spectra (in the $3500-1200 \mathrm{~cm}^{-1}$ wavelength range with a $4 \mathrm{~cm}^{-1}$ resolution) of a "flight sun-exposed" sample of glycine + iron-rich phase before (black) and after (gray) compared to a "flight dark control". (a.u.= arbitrary units). 
The recovery ratios (Fig. 8) of the "flight dark control" samples are higher than $90 \%$ (except for one sample of glycine). This ratio is consistent with the ground DLR control samples, meaning that the potential degradation from SEP and GCR is not significant according to our experiments and sensibility of our instrument.

\subsection{Adenine}

Adenine samples exposed to solar UV radiation are photodissociated. FTIR spectra do not present new bands, and we concluded that no new solid compound was produced. The average $A / A_{0}$ recovery ratio of the two flight sun-exposed samples is $90 \%$ after subtraction of the average recovery ratio of the flight dark control samples. The quantum efficiency of photodecomposition is about $2.1 \times 10^{-5}$ molecules $\cdot$ photon $^{-1}$ (Table 1). In their previous laboratory experiments, Poch et al. obtained an average value around $1.1 \times 10^{-4}$ molecules $\cdot$ photon $^{-1}$, meaning a factor of 5 between the two sets of data (Poch et al., 2014). But if we consider the high error bars of the laboratory simulations of the MOMIE experiment, then the quantum efficiency of photodecomposition of the two experiments is of the same order of magnitude. Finally, the PSS experiment reduced the error bars of the quantum efficiency of adenine photolysis compared to the laboratory data.

\subsection{Adenine and martian simulant}

Adenine + iron-rich martian simulant samples did not produce any new solid compounds (from FTIR data). They have a similar average recovery ratio of $90 \%$ considering the two flight sun-exposed samples and the subtraction of the recovery ratio of the flight dark control samples. Fewer solar UV photons reached the adenine deposits for these samples because the martian simulant deposit absorbed a significant amount of them. The UV transmission in the range 200$250 \mathrm{~nm}$ by the martian simulant is between $21 \%$ and $22 \%$ (Fig. 9). The adenine deposits of these samples received approximatively 5 times fewer photons than the pure adenine samples. Their quantum efficiency of photodecomposition is around $1 \times 10^{-4}$ molecules $\cdot$ photon $^{-1}$. This value is 5 times higher than for pure adenine samples $\left(2.1 \times 10^{-5}\right.$ molecules $\cdot$ photon $^{-1}$ ). These results show that the martian simulant deposits did not have a protective effect for the samples studied in the PSS experiment, but on the contrary its presence increases the photodegradation of adenine. We can assume that this photodegradation is produced by photooxidation processes. The same result has been observed in one of our previous experiments in LEO with an amino acid $(\alpha-$ aminoisobutyric acid) and a carboxylic acid (phthalic acid) in the presence of the JSC Mars-1 martian simulant (Stalport et al., 2010). The interaction of UV radiation and the iron-rich phase seems to be a catalyzer of the sample photodecomposition. Photocatalytic oxidation can be responsible for organic degradation of organic compounds in ordinary terrestrial soils (Sancier and Wise, 1981). Our experiments showed that an iron-rich martian simulant may play a role in the photocatalytic degradation of organic compounds on Mars. Several laboratory experiments investigated the interaction of UV radiation with a mineral matrix (Chun et al., 1978; Pang et al.,

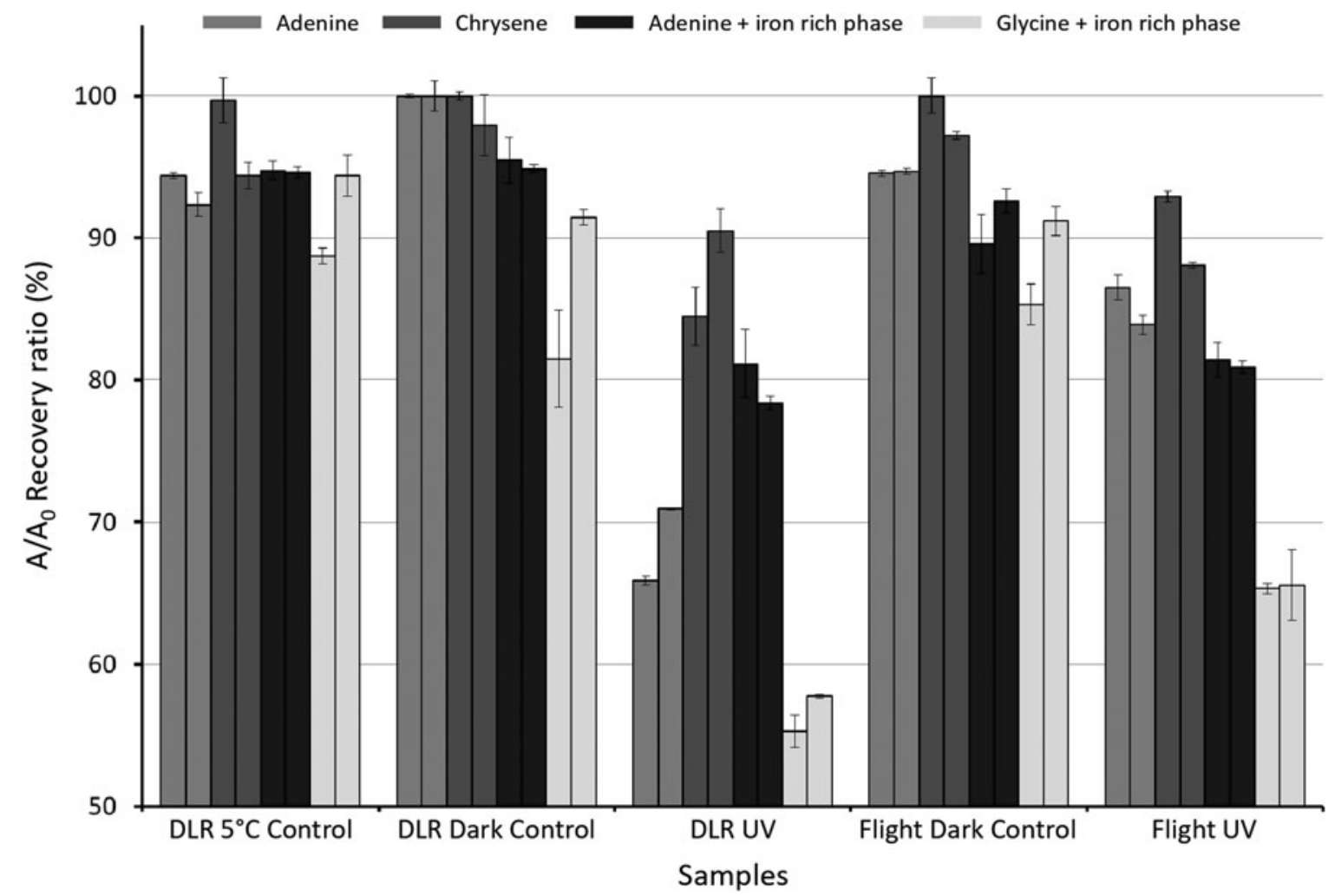

FIG. 8. $A / A_{0}$ recovery ratio of the DLR $\left(5^{\circ} \mathrm{C}\right.$, dark control, UV exposed) and PSS (flight dark control, flight sun-exposed) samples calculated from FTIR spectra. In gray, adenine; in dark gray, chrysene; in black, adenine + iron-rich phase; in light gray, glycine + iron-rich phase. 


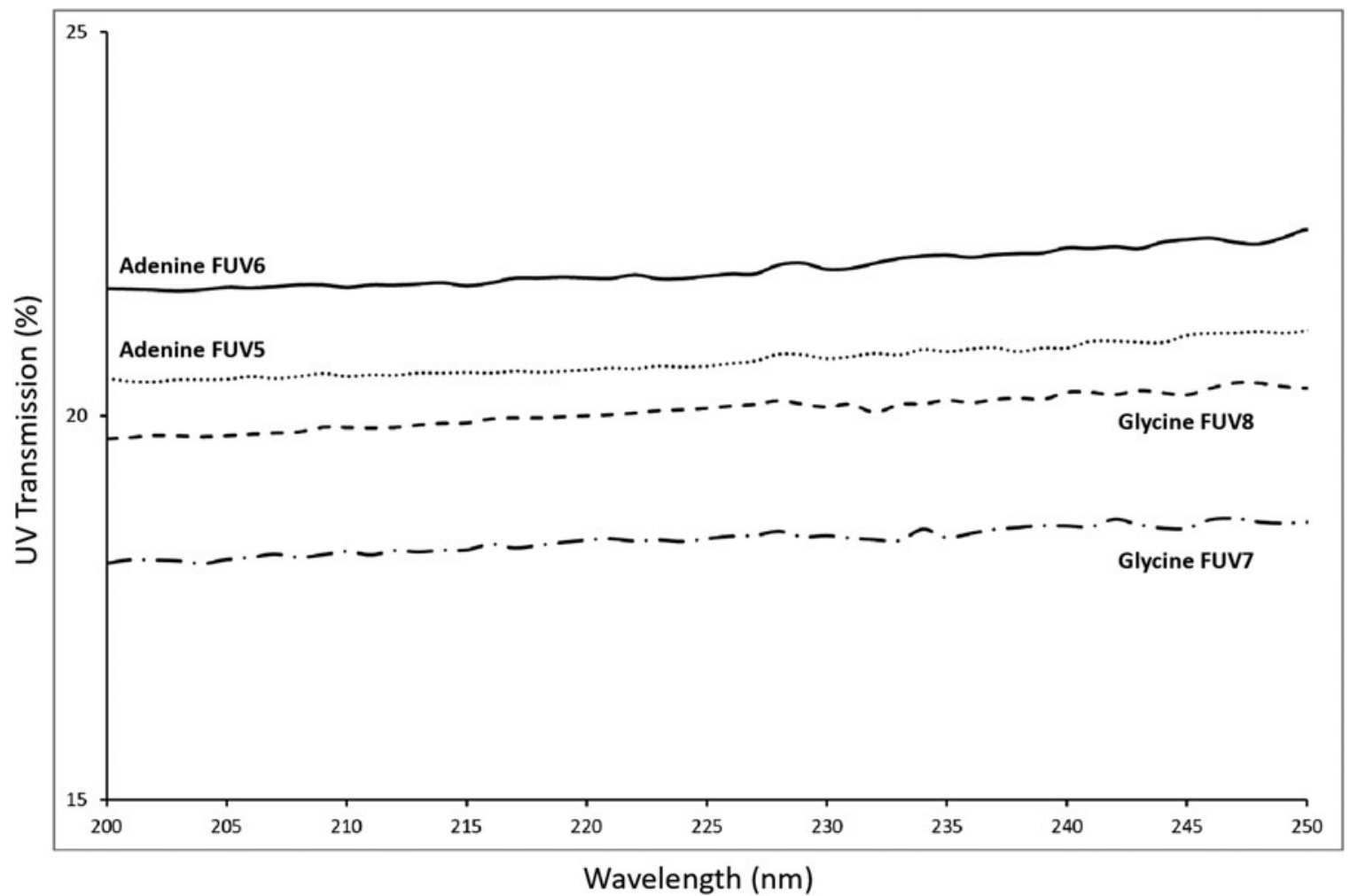

FIG. 9. UV transmission of iron-rich phase deposits for flight UV-exposed samples (glycine and adenine).

1982; Yen et al., 2000). Yen et al. (2000) showed that the interaction of UV radiation with an oxygen-rich mineral matrix could produce one or more inorganic superoxides or peroxides able to destroy the organic matter. Chun et al. (1978) and Pang et al. (1982) showed also that oxidation of organics by oxides is photocatalyzed by UV radiation. Dos Santos et al. (2016) conclude in their study that minerals containing ferrous iron preserved the lowest amount of organic molecules such as amino acids, which is explained by iron (II)-catalyzed reactions with reactive oxygen species generated under Mars-like conditions especially initiated by UV radiation (dos Santos et al., 2016).

\subsection{Glycine}

Glycine samples exposed to solar UV radiation did not produce any new solid compound (from FTIR data). Their average recovery ratio is $77 \%$ considering the two flight sunexposed samples and the subtraction of the average recovery ratio of the flight dark control samples. These samples have an iron-rich martian simulant deposit that absorbs a significant part of the solar UV photons. Their UV transmission in the range $200-250 \mathrm{~nm}$ is between $18 \%$ and $20 \%$. The quantum efficiency of photodecomposition of glycine is around $8 \times 10^{-3}$ molecules $\cdot$ photon $^{-1}$ (Table 1 ). This value is very close to our previous laboratory data (Poch et al., 2014). We estimated an experimental quantum efficiency of photodecomposition between 6 and $7 \times 10^{-3}$ molecules $\cdot$ photon ${ }^{-1}$. These close values could indicate that the iron-rich martian simulant has a very limited impact on the photodecomposition of glycine. However, the error bars for these laboratory experiments are also very high, and it is possible that this mineral phase significantly increases the degradation yield of glycine. Laboratory experiments from dos Santos et al. (2016) showed that an iron-rich phase such as basaltic lava preserved the lowest amount of organic molecules such as amino acids. The comparison of both LEO and our previous laboratory data (Poch et al., 2014) could not confirm a significant impact of the iron-rich martian simulant, but if we consider the results of dos Santos et al. (2016), we need to perform more laboratory experiments to conclude on this point.

\subsection{Chrysene}

Chrysene samples exposed to solar UV radiation did not produce any new solid compounds (from FTIR data). Their recovery ratios are between $94 \%$ and $89 \%$ considering the two flight sun-exposed samples and the subtraction of the recovery ratio of the flight dark control samples. The quantum efficiency of photodecomposition is estimated around $2.3 \times 10^{-5}$ molecules $\cdot$ photon $^{-1}$ (Table 1$)$. This value is very close to laboratory data from Poch et al. (2014). The authors estimated this quantum efficiency of photodecomposition around $5 \times 10^{-5}$ molecules $\cdot$ photon ${ }^{-1}$. Poch et al. (2014) gave the quantum efficiency of photodecomposition of only one sample, and the error bar is also very high, but LEO and laboratory values are of the same order of magnitude. We will perform more laboratory experiments to confirm the value of the quantum efficiency of photodecomposition of chrysene.

Finally, the good correlation of the data (for pure organic molecule samples) between LEO and laboratory experiments shows their robustness and validates the analytical protocols we developed for these experiments. The other aspect of experiments in LEO is that the uncertainties on the calculations of the quantum efficiencies of photodecomposition are significantly lower. The main reason for this reduction is the 
higher variability of UV sources in the laboratory, while solar UV radiation in the $200-250 \mathrm{~nm}$ range is much more stable even during two years of exposure in space.

\section{Implications for the Search for Organic Molecules on Mars}

The sources of organic matter on the surface of Mars show that the organic molecular diversity detected by the various space probes (landers, rovers, and orbiters) on the surface of this planet does not represent the expected one. If we consider that no biological or prebiotic chemistry activity has appeared on the surface of Mars, organic molecules from the interplanetary medium should be present. The organic molecules detected by the SAM instrument such as chlorinated or thiophenic compounds (Freissinet et al., 2015; Eigenbrode et al., 2018) are not molecules brought directly from the interplanetary medium. Similarly, their link with potential martian abiotic organic synthesis or biological activity has not been demonstrated. The methods of extraction of organic matter by the SAM instrument from solid samples could explain the production of these compounds from endogenous parent organic molecules. For example, chlorobenzene is thought to originate from a combination of chlorine and carbon (Hecht et al., 2009; Glavin et al., 2013), and this reaction could be done in the SAM ovens during the pyrolysis of the sample. Therefore, the precursor (or precursors) of the detected chlorobenzene remains unknown, and we can only speculate on its (or their) structure (or structures). However, the abundance of chlorobenzene $(300 \mathrm{ppb})$ is below what is expected to be found at Mars' surface from meteoritic infall only (Benner et al., 2000). Therefore, the radiative and oxidizing environment of the martian surface certainly plays a major role in the preservation of organic matter, and we thus consider that a significant fraction of the organics was previously altered. It is therefore important to perform more experimental simulations of the evolution of a larger number of organic molecules. We must consider different sinks of organic matter (ionizing radiation in synergy with oxidizing species) according to the depth in the martian regolith. Since 2012, samples collected and analyzed by the Mars Science Laboratory instruments come from the first centimeters. Considering the penetration depths of different radiation sources reaching the surface of Mars, it is likely that a very large fraction of the organic matter in the samples collected is altered. Assuming that the deeper the samples are collected, the greater the probability of extracting pristine organic matter is, the next mission to Mars, ExoMars 2020, could then allow the detection of a wider molecular diversity. Indeed, one of the instruments on board the rover of this mission will have the possibility to dig up to $2 \mathrm{~m}$ deep (Vago et al., 2017).

\section{Conclusions}

Organic molecules of astrobiological interest were exposed to space conditions. Our study was more focused on solar UV photons. We used a filtered UV solar spectrum during the PSS LEO experiment to mimic the UV radiation reaching the surface of Mars. Some of the samples were selected to study the behavior and stability of organic molecules (glycine, adenine, chrysene) that may be present on Mars. The FTIR results showed that the direct exposure to filtered solar UV radiation for almost 2 years led to the partial photodegradation of these organics. The presence of an iron-rich martian simulant has a direct impact on the evolution of adenine, but it is more questionable for glycine. Laboratory experiments confirmed these results for pure organic deposits and also provided crucial kinetic parameters to understand the preservation rates of organic matter at the surface of Mars. Poch et al. (2014) showed that halflives are dependent of the thickness of the organic deposit especially if it is not optically thin, meaning UV transmission is not $>90 \%$, and then almost all the molecules of the sample are not irradiated at the same time. For the PSS experiment, the UV transmission data showed that the organic deposits are not optically thin. We choose to produce thick deposits to be sure the sample would not be completely photodegraded at the end of the mission.

We choose to work with the quantum efficiency of photodecomposition because it is most appropriate to compare the evolution of our samples in both LEO and laboratory experiments. These data can be estimated from the number of photons reaching a sample and the number of molecules photodegraded. Our values of quantum efficiency of photodecomposition of adenine, glycine, and chrysene from both laboratory and space simulations are very consistent, meaning the robustness of these experiments. Such data can be used to estimate the amount of these organic compounds in the martian regolith over time. The accumulation of such organic molecules would be due to the difference between their production/intake rates such as meteoritic infall, which have been estimated to between $2.4 \times 10^{7} \mathrm{~g} \cdot \mathrm{yr}^{-1}$ (Benner et al., 2000) and $2.4 \times 10^{8} \mathrm{~g} \cdot \mathrm{yr}^{-1}$ (Flynn, 1996), and the different pathways that may lead to their destruction (UV radiation, for example). Assuming that the organic compounds were uniformly deposited at the surface of Mars and mixed with the regolith up to $1 \mathrm{~cm}$ deep (UV radiation is believed to penetrate only the first millimeter of the martian regolith, except in water ice, where the penetration would be several centimeters [Cockell and Raven, 2004]) and only a few centimeters of the soil would be recycled by winds, then the maximal concentration of organics by weight would be less than $1 \mathrm{ppt}$ (with a maximal repartition on the surface of Mars of about $3 \times 10^{-7} \mathrm{~g} \cdot \mathrm{m}^{-2}$ and a density of the martian regolith of about $4 \mathrm{~g} \cdot \mathrm{cm}^{-3}$ ) (see also Stalport et al., 2010). Finally, the quantum efficiencies of photodecomposition of these molecules and also other organic compounds from both our future laboratory and space experiments are actually implemented into a model we are developing. It focuses on the concentration of organic matter at the surface of Mars according to the regolith depth, latitude, longitude, and seasons. For example, the latitudinal variation of the relative UV environment will modify degradation rate of organic matter as it depends on the quantity of photons interacting with the organic molecules (Laurent et al., 2019). The goal of this model is to predict which compounds at what level could be detected on Mars by in situ mission, and what their origin (biotic versus abiotic) might be. More data about this model will be presented in future papers.

\section{Acknowledgments}

This study was supported by the French "Centre National de la Recherche Scientifique" (CNRS) and by the French Space 
Agency "Centre National d'Etudes Spatiales" (CNES). We also would like to thank the reviewers for their thoughtful comments and efforts toward improving our manuscript.

\section{Disclosure Statement}

No competing financial interests exist.

\section{References}

Allen, C.C., Morris, R.V., Jager, K.M., Golden, D.C., Lindstrom, D.J., Lindstrom, M.M., and Lockwood, J.P. (1998) Martian regolith simulant JSC Mars-1 [abstract 1690]. In $29^{\text {th }}$ Lunar and Planetary Science Conference, Lunar and Planetary Institute, Houston.

Altwegg, K., Balsiger, H., Bar-Nun, A., Berthelier, J.-J., Bieler, A., Bochsler, P., Briois, C., Calmonte, U., Combi, M.R., Cottin, H., De Keyser, J., Dhooghe, F., Fiethe, B., Fuseller, S.A., Gasc, S., Gombosi, T.I., Hansen, K.C., Haessig, M., Jäckel, A., Kopp, E., Korth, A., Le Roy, L., Mall, U., Marty, B., Mousis, O., Owen, T., Rème, H., Rubin, M., Sémon, T., Tzou, C.Y., Hunter Waite, J., and Wurz, P. (2016) Prebiotic chemicals-amino acid and phosphorus - in the coma of comet 67P/ChuryumovGerasimenko. Sci Adv 2, doi:10.1126/sciadv.1600285.

Barbatti, M. and Ullrich, S. (2011) Ionization potentials of adenine along the internal conversion pathways. Phys Chem Chem Phys 13:15492-15500.

Barbier, B., Henin, O., Boillot, F., Chabin, A., Chaput, D., and Brack, A. (2002) Exposure of amino acids and derivatives in the Earth orbit. Planet Space Sci 50:353-359.

Benner, S.A., Devine, K.G., Matveeva, L.N., and Powell, D.H. (2000) The missing organic molecules on Mars. Proc Natl Acad Sci USA 97:2425-2430.

Biemann, K. (1979) The implications and limitations of the findings of the Viking organic analysis experiment. $J \mathrm{Mol}$ Evol 14:65-70.

Botta, O. (2005) Organic chemistry in meteorites, comets, and the interstellar medium. In Astrochemistry: Recent Successes and Current Challenges, Proceedings of the $231^{\text {st }}$ Symposium of the International Astronomical Union, edited by D.C. Lis, G.A. Blake, and E. Herbst, Cambridge University Press, Cambridge, UK, pp 479-488.

Botta, O. and Bada J.L. (2002) Extraterrestrial organic compounds in meteorites. Surveys in Geophysics 23:411-467.

Brinton, K.L.F., Engrand, C., Glavin, D.P., Bada, J.L., and Maurette, M. (1998) A search for extraterrestrial amino acids in carbonaceous Antarctic micrometeorites. Orig Life Evol Biosph 28:413-424.

Callahan, M.P., Smith, K.E., Cleaves, H.J., Ruzicka, J., Stern, J.C., Glavin, D.P., House, C.H., and Dworkin, J.P. (2011) Carbonaceous meteorites contain a wide range of extraterrestrial nucleobases. Proc Natl Acad Sci USA 108:13995-13998.

Chun, S.F.S., Pang, K.D., and Cutts, J.A. (1978) Photocatalytic oxidation of organic compounds on Mars. Nature 274:875876.

Clemett, S.J., Chillier, X.D.F., Gillette, S., Zare, R.N., Maurette, M., Engrand, C., and Kurat, G. (1998) Observation of indigenous polycyclic aromatic hydrocarbons in 'giant' carbonaceous Antarctic micrometeorites. Orig Life Evol Biosph 28:425-448.

Cochran, A.L., Levasseur-Regourd, A.-C., Cordiner, M., Hadamcik, E., Lasue, J., Gicquel, A., Schleicher, D.G., Charnley, S.B., Mumma, M.J., Paganini, L., Bockelée-Morvan, D., Biver, N., and Kuan, Y.-J. (2015) The composition of comets. Space Sci Rev 197:9-46.
Cockell, C.S. and Raven, J.A. (2004) Zones of photosynthetic potential on Mars and the early Earth. Icarus 169:300-310.

Cockell, C.S., Catling, D.C., Davis, W.L., Snook, K., Kepner, R.L., Lee, P., and McKay, C.P. (2000) The ultraviolet environment of Mars: biological implications past, present, and future. Icarus 146:343-359.

Cottin, H., Coll, P., Coscia, D., Fray, N., Guan, Y.Y., Macari, F., Raulin, F., Rivron, C., Stalport, F., Szopa, C., Chaput, D., Viso, M., Bertrand, M., Chabin, A., Thirkell, L., Westall, F., and Brack, A. (2008) Heterogeneous solid/gas chemistry of organic compounds related to comets, meteorites, Titan, and Mars: laboratory and in lower Earth orbit experiments. $A d v$ Space Res 42:2019-2035.

Cottin, H., Noblet, A., Guan, Y.Y., Poch, O., Saiagh, K., Cloix, M., Macari, F., Jérome, M., Coll, P., Raulin, F., Stalport, F., Szopa, C., Bertrand, M., Chabin, A., Westall, F., Chaput, D., Demets, R., and Brack, A. (2012) The PROCESS experiment: an astrochemistry laboratory for solid and gaseous organic samples in low Earth orbit. Astrobiology 12:412-425.

Cottin, H., Kotler, J.M., Billi, D., Cockell, C., Demets, R., Ehrenfreund, P., Elsaesser, A., d'Hendecourt, L., van Loon, J.J.W.A., Martins, Z., Onofri, S., Quinn, R.C., Rabbow, E., Rettberg, P., Ricco, A.J., Slenzka, K., de la Torre, R., de Vera, J.-P., Westall, F., Carrasco, N., Fresneau, A., Kawaguchi, Y., Kebukawa, Y., Nguyen, D., Poch, O., Saiagh, K., Stalport, F., Yamagishi, A., Yano, H., and Klamm, B.A. (2017) Space as a tool for astrobiology: review and recommendations for experimentations in Earth orbit and beyond. Space Sci Rev 209:83-181.

Dartnell, L.R., Desorgher, L., Ward, J.M., and Coates, A.J. (2007) Modelling the surface and subsurface martian radiation environment: implications for astrobiology. Geophys Res Lett 34, doi:10.1029/2006GL027494.

Dartois, E., Engrand, C., Brunetto, R., Duprat, J., Pino, T., Quirico, E., Remusat, L., Bardin, N., Briani, G., Mostefaoui, S., Morinaud, G., Crane, B., Szwec, N., Delauche, L., Jamme, F., Sandt, Ch., and Dumas, P. (2013) UltraCarbonaceous Antarctic micrometeorites, probing the Solar System beyond the nitrogen snow-line. Icarus 224:243-252.

Demets, R., Schulte, W., and Baglioni, P. (2005) The past, present and future of Biopan. Adv Space Res 36:311-316.

dos Santos, R., Patel, M., Cuadros, J., and Martins, Z. (2016) Influence of mineralogy on the preservation of amino acids under simulated Mars conditions. Icarus 277:342-353.

Ehresmann, B., Zeitlin, C.J., Hassler, D.M., Matthiä, D., Guo, J., Wimmer-Schweingruber, R.F., Appel, J.K., Brinza, D.E., Rafkin, S.C.R., Böttcher, S.I., Burmeister, S., Lohf, H., Martin, C., Böhm, E., and Reitz, G. (2017) The charged particle radiation environment on Mars measured by MSL/ RAD from November 15, 2015 to January 15, 2016. Life Sci Space Res 14:3-11.

Eigenbrode, J.L., Summons, R.E., Steele, A., Freissinet, C., Millan, M., Navarro-González, R., Sutter, B., McAdam, A.C., Franz, H.B., Glavin, D.P., Archer, P.D., Mahaffy, P.R., Conrad, P.G., Hurowitz, J.A., Grotzinger, J.P., Gupta, S., Ming, D.W., Sumner, D.Y., Szopa, C., Malespin, C., Buch, A., and Coll, P. (2018) Organic matter preserved in 3-billion-year-old mudstones at Gale Crater, Mars. Science 360:1096-1101.

Elsila, J.E., Glavin, D.P., and Dworkin, J.P. (2009) Cometary glycine detected in samples returned by Stardust. Meteorit Planet Sci 44:1323-1330.

Flynn, G.J. (1996) The delivery of organic matter from asteroids and comets to the early surface of Mars. Earth Moon Planets 72:469-474. 
Freissinet, C., Glavin, D.P., Mahaffy, P.R., Miller, K.E., Eigenbrode, J.L., Summons, R.E., Brunner, A.E., Buch, A., Szopa, C., Archer, P.D., Jr., Franz, H.B., Atreya, S.K., Brinckerhoff, W.B., Cabane, M., Coll, P., Conrad, P.G., Des Marais, D.J., Dworkin, J.P., Fairén, A.G., François, P., Grotzinger, J.P., Kashyap, S., ten Kate, I.L., Leshin, L.A., Malespin, C.A., Martin, M.G., Martin-Torres, J.F., McAdam, A.C., Ming, D.W., Navarro-González, R., Pavlov, A.A., Prats, B.D., Squyres, S.W., Steele, A., Stern, J.C., Sumner, D.Y., Sutter, B., Zorzano, M.-P.; MSL Science Team. (2015) Organic molecules in the Sheepbed Mudstone, Gale Crater, Mars. J Geophys Res Planets 120:495-514.

Glavin, D.P., Matrajt, G., and Bada, J.L. (2004) Re-examination of amino acids in Antarctic micrometeorites. Adv Space Res 33:106-113.

Glavin, D.P., Freissinet, C., Miller, K.E., Eigenbrode, J.L., Brunner, A.E., Buch, A., Sutter, B., Archer, P.D., Atreya, S.K., Brinckerhoff, W.B., Cabane, M., Coll, P., Conrad, P.G., Coscia, D., Dworkin, J.P., Franz, H.B., Grotzinger, J.P., Leshin, L.A., Martin, M.G., McKay, C., Ming, D.W., NavarroGonzalez, R., Pavlov, A., Steele, A., Summons, R.E., Szopa, C., Teinturier, S., and Mahaffy, P.R. (2013) Evidence for perchlorates and the origin of chlorinated hydrocarbons detected by SAM at the Rocknest aeolian deposit in Gale Crater. J Geophys Res Planets 118:1955-1973.

Gómez-Elvira, J., Armiens, C., Carrasco, I., Genzer, M., Gómez, F., Haberle, R., Hamilton, V.E., Harri, A.-M., Kahanpää, H., Kemppinen, O., Lepinette, A., Martín Soler, J., Martín-Torres, J., Martínez-Frías, J., Mischna, M., Mora, L., Navarro, S., Newman, C., de Pablo, M.A., Peinado, V., Polkko, J., Rafkin, S.C.R., Ramos, M., Rennó, N., Richardson, M., Rodríguez-Manfredi, J.A., Romeral Planelló, J.J., Sebastián, E., de la Torre, M., Torres, J., Urqui, R., Vasavada, A.R., Verdasca, J., and Zorzano, M.-P. (2014) Curiosity's rover environmental monitoring station: overview of the first 100 sols. J Geophys Res Planets 119:1680-1688.

Gontareva, N.B. (2005) Photochemical stability of biomolecules in the experiments modelling martian surface conditions. Int J Astrobiol 4:93-96.

Guan, Y.Y., Fray, N., Coll, P., Macari, F.D.R., Chaput, D., Raulin, F.O., and Cottin, H. (2010) UVolution: compared photochemistry of prebiotic organic compounds in low Earth orbit and in the laboratory. Planet Space Sci 58:1327-1346.

Guzman, M., McKay, C.P., Quinn, R.C., Szopa, C., Davila, A.F., Navarro-González, R., and Freissinet, C. (2018) Identification of chlorobenzene in the Viking gas chromatographmass spectrometer data sets: reanalysis of Viking Mission data consistent with aromatic organic compounds on Mars. $J$ Geophys Res Planets 123:1674-1683.

Hayatsu, R., Studier, M.H., Moore, L.P., and Anders, E. (1975) Purines and triazines in the Murchison meteorite. Geochim Cosmochim Acta 39:471-488.

Hecht, M.H., Kounaves, S.P., Quinn, R.C., West, S.J., Young, S.M.M., Ming, D.W., Catling, D.C., Clark, B.C., Boynton, W.V., Hoffman, J., Deflores, L.P., Gospodinova, K., Kapit, J., and Smith, P.H. (2009) Detection of perchlorate and the soluble chemistry of martian soil at the Phoenix lander site. Science 325:64-67.

Kuhn, W.R. and Atreya S.K. (1979) Solar radiation incident on the martian surface. J Mol Evol 14:57-64.

Lasne, J., Noblet, A., Szopa, C., Navarro-González, R., Cabane, M., Poch, O., Stalport, F., François, P., Atreya, S.K., and Coll, P. (2016) Oxidants at the surface of Mars: a review in light of recent exploration results. Astrobiology 16:977-996.
Laurent, B., Cousins, C.R., Pereira, M.F.C., and Martins, Z. (2019) Effects of UV-organic interaction and martian conditions on the survivability of organics. Icarus 323:33-39.

Martins, Z. (2019) Organic molecules in meteorites and their astrobiological significance. In Handbook of Astrobiology, edited by V.M. Kolb, CRC Press, Boca Raton, FL, pp 177-194.

Martins, Z. and Sephton M.A. (2009) Extraterrestrial amino acids. In Amino Acids, Peptides and Proteins in Organic Chemistry, edited by A.B. Hughes, Wiley-VCH, Weinheim, Germany, pp 3-42.

Martins, Z., Alexander, C.M.O.D., Orzechowska, G.E., Fogel, M.L., and Ehrenfreund, P. (2007) Indigenous amino acids in primitive CR meteorites. Meteorit Planet Sci 42:2125-2136.

Martins, Z., Modica, P., Zanda, B., and D'Hendecourt, L.L.S. (2015) The amino acid and hydrocarbon contents of the Paris meteorite: insights into the most primitive $\mathrm{CM}$ chondrite. Meteorit Planet Sci 50:926-943.

Mumma, M.J. and Charnley S.B. (2011) The chemical composition of comets-emerging taxonomies and natal heritage. Annu Rev Astron Astrophys 49:471-524.

Naraoka, H., Shimoyama, A., and Harada, K. (2000) Isotopic evidence from an Antarctic carbonaceous chondrite for two reaction pathways of extraterrestrial PAH formation. Earth Planet Sci Lett 184:1-7.

Navarro-González, R., Navarro, K.F., de la Rosa, J., Iñiguez, E., Molina, P., Miranda, L.D., Morales, P., Cienfuegos, E., Coll, P., Raulin, F., Amils, R., and McKay, C.P. (2006) The limitations on organic detection in Mars-like soils by thermal volatilizationgas chromatography-MS and their implications for the Viking results. Proc Natl Acad Sci USA 103:16089-16094.

Navarro-González, R., Vargas, E., de la Rosa, J., Raga, A.C., and McKay, C.P. (2010) Reanalysis of the Viking results suggests perchlorate and organics at midlatitudes on Mars. $J$ Geophys Res Planets 115, doi:10.1029/2010JE003599.

Noblet, A., Stalport, F., Guan, Y.Y., Poch, O., Coll, P., Szopa, C., Cloix, M.G., Macari, F.D.R., Raulin, F., Chaput, D., and Cottin, H. (2012) The PROCESS experiment: amino and carboxylic acids under Mars-like surface UV radiation conditions in low-Earth orbit. Astrobiology 12:436-444.

Pang, K.D., Chun, S.F.S., Ajello, J.M., Nansheng, Z., and Minji, L. (1982) Organic and inorganic interpretations of the martian ultraviolet infrared reflectance spectrum. Nature 295:43-46.

Patel, M.R., Zarnecki, J.C., and Catling, D.C. (2002) Ultraviolet radiation on the surface of Mars and the Beagle 2 UV sensor. Planet Space Sci 50:915-927.

Pavlov, A.A., Vasilyev, G., Ostryakov, V.M., Pavlov, A.K., and Mahaffy, P. (2012) Degradation of the organic molecules in the shallow subsurface of Mars due to irradiation by cosmic rays. Geophys Res Lett 39, doi:10.1029/2012GL052166.

Perun, S., Sobolewski, A.L., and Domcke, W. (2005) Photostability of $9 \mathrm{H}$-adenine: mechanisms of the radiationless deactivation of the lowest excited singlet states. Chem Phys 313:107-112.

Poch, O., Noblet, A., Stalport, F., Correia, J.J., Grand, N., Szopa, C., and Coll, P. (2013) Chemical evolution of organic molecules under Mars-like UV radiation conditions simulated in the laboratory with the "Mars Organic Molecule Irradiation and Evolution”, (MOMIE) setup. Planet Space Sci 85:188-197.

Poch, O., Kaci, S., Stalport, F., Szopa, C., and Coll, P. (2014) Laboratory insights into the chemical and kinetic evolution of several organic molecules under simulated Mars surface UV radiation conditions. Icarus 242:50-63.

Poch, O., Jaber, M., Stalport, F., Nowak, S., Georgelin, T., Lambert, J.-F., Szopa, C., and Coll, P. (2015) Effect of 
nontronite smectite clay on the chemical evolution of several organic molecules under simulated martian surface ultraviolet radiation conditions. Astrobiology 15:221-237.

Rabbow, E., Rettberg, P., Barczyk, S., Bohmeier, M., Parpart, A., Panitz, C., Horneck, G., von Heise-Rotenburg, R., Hoppenbrouwers, T., Willnecker, R., Baglioni, P., Demets, R., Dettmann, J., and Reitz, G. (2012) EXPOSE-E, an ESA astrobiology mission 1.5 years in space. Astrobiology 12:374-386.

Rabbow, E., Rettberg, P., Parpart, A., Panitz, C., Schulte, W., Molter, F., Jaramillo, E., Demets, R., Weiß, P., and Willnecker, R. (2017) EXPOSE-R2: the astrobiological ESA mission on board of the International Space Station. Front Microbiol 8, doi:10.3389/fmicb.2017.01533.

Rieder, R., Economou, T., Wanke, H., Turkevich, A., Crisp, J., Breckner, J., Dreibus, G., and McSween, H.Y., Jr. (1997) The chemical composition of martian soil and rocks returned by the mobile alpha proton X-ray spectrometer: preliminary results from the X-ray mode. Science 278:1771-1774.

Roy, D., Najafian, K., and von Ragué Schleyer, P. (2007) Chemical evolution: the mechanism of the formation of adenine under prebiotic conditions. Proc Natl Acad Sci USA 104:17272-17277.

Sancier, K.M. and Wise, H. (1981) Photoassisted oxidation of organic material catalyzed by sand. Atmospheric Environment 15:639-640.

Schmitt-Kopplin, P., Gabelica, Z., Gougeon, R.G.D., Fekete, A., Kanawati, B., Harir, M., Gebefuegi, I., Eckel, G., and Hertkorn, N. (2010) High molecular diversity of extraterrestrial organic matter in Murchison meteorite revealed 40 years after its fall. Proc Natl Acad Sci USA 107:2763-2768.

Shkrob, I.A., Chemerisov, S.D., and Marin, T.W. (2010) Photocatalytic decomposition of carboxylated molecules on light-exposed martian regolith and its relation to methane production on Mars. Astrobiology 10:425-436.

Stalport, F., Coll, P., Szopa, C., and Raulin, F. (2008) Search for organic molecules at the Mars surface: the "Martian Organic Material Irradiation and Evolution" (MOMIE) project. Adv Space Res 42:2014-2018.

Stalport, F., Coll, P., Szopa, C., Cottin, H., and Raulin, F. (2009) Investigating the photostability of carboxylic acids exposed to Mars surface ultraviolet radiation conditions. Astrobiology 9:543-549.

Stalport, F., Guan, Y.Y., Coll, P., Szopa, C., Macari, F.D.R., Raulin, F.O., Chaput, D., and Cottin, H. (2010) UVolution, a photochemistry experiment in low Earth orbit: investigation of the photostability of carboxylic acids exposed to Mars surface UV radiation conditions. Astrobiology 10:449-461.

Steele, A., McCubbin, F.M., Fries, M., Kater, L., Boctor, N.Z., Fogel, M.L., Conrad, P.G., Glamoclija, M., Spencer, M., Morrow, A.L., Hammond, M.R., Zare, R.N., Vicenzi, E.P., Siljeström, S., Bowden, R., Herd, C.D., Mysen, B.O., Shirey, S.B., Amundsen, H.E., Treiman, A.H., Bullock, E.S., and Jull, A.J. (2012) A reduced organic carbon component in martian basalts. Science 337:212-215.

Stoker, C.R. and Bullock, M.A. (1997) Organic degradation under simulated martian conditions. J Geophys Res 102: 10881-10888.

ten Kate, I.L., Garry, J.R.C., Peeters, Z., Quinn, R., Foing, B., and Ehrenfreund, P. (2005) Amino acid photostability on the martian surface. Meteorit Planet Sci 40:1185-1193.

ten Kate, I.L., Garry, J.R.C., Peeters, Z., Foing, B., and Ehrenfreund, P. (2006) The effects of martian near surface conditions on the photochemistry of amino acids. Planet Space Sci 54:296-302.

Vago, J.L., Westall, F., Coates, A.J., Jaumann, R., Korablev, O., Ciarletti, V., Mitrofanov, I., Josset, J.-L., De Sanctis, M.C., Bibring, J.-P., Rull, F., Goesmann, F., Steininger, H., Goetz, W., Brinckerhoff, W., Szopa, C., Raulin, F., Westall, F., Edwards, H.G.M., Whyte, L.G., Fairén, A.G., Bibring, J.-P., Bridges, J., Hauber, E., Ori, G.G., Werner, S., Loizeau, D., Kuzmin, R.O., Williams, R.M.E., Flahaut, J., Forget, F., Vago, J.L., Rodionov, D., Korablev, O., Svedhem, H., Sefton-Nash, E., Kminek, G., Lorenzoni, L., Joudrier, L., Mikhailov, V., Zashchirinskiy, A., Alexashkin, S., Calantropio, F., Merlo, A., Poulakis, P., Witasse, O., Bayle, O., Bayón, S., Meierhenrich, U., Carter, J., GarcíaRuiz, J.M., Baglioni, P., Haldemann, A., Ball, A.J., Debus, A., Lindner, R., Haessig, F., Monteiro, D., Trautner, R., Voland, C., Rebeyre, P., Goulty, D., Didot, F., Durrant, S., Zekri, E., Koschny, D., Toni, A., Visentin, G., Zwick, M., van Winnendael, M., Azkarate, M., Carreau, C.; ExoMars Project Team. (2017) Habitability on early Mars and the search for biosignatures with the ExoMars rover. Astrobiology 17: 471-510.

Yen, A.S., Kim, S.S., Hecht, M.H., Frant, M.S., and Murray, B. (2000) Evidence that the reactivity of the martian soil is due to superoxide ions. Science 289:1909-1912.

Zolotov, M. and Shock, E. (1999) Abiotic synthesis of polycyclic aromatic hydrocarbons on Mars. J Geophys Res 104: 14033-14050.

Address correspondence to: Fabien Stalport LISA

Universités Paris Est Créteil and Paris Diderot CNRS

Institut Pierre Simon Laplace UMR 7583

61 avenue du Général de Gaulle 94010 Créteil cedex France

E-mail: fabien.stalport@lisa.u-pec.fr

Submitted 17 December 2018 Accepted 12 June 2019

$\begin{aligned} & \text { Abbreviations Used } \\ & \text { DLR }=\text { German Aerospace Center } \text { FTIR }=\text { Fourier transform infrared } \\ & \text { GCR }=\text { galactic cosmic rays } \\ & \mathrm{IR}=\text { infrared } \\ & \mathrm{ISS}=\text { International Space Station } \\ & \mathrm{LEO}=\text { low Earth orbit } \\ & \mathrm{MGR}=\text { Mission Ground Reference } \\ & \mathrm{MOMIE}=\text { Mars Organic Molecules Irradiation } \\ & \text { and Evolution } \\ & \mathrm{MUSC}=\text { Microgravity User Support Center } \\ & \mathrm{PAH}=\text { polycyclic aromatic hydrocarbon } \\ & \mathrm{PSS}=\text { Photochemistry on the Space Station } \\ & \mathrm{SAM}=\text { Sample Analysis at Mars } \\ & \mathrm{SEP}=\text { solar energetic particles } \\ & \mathrm{UV}=\text { ultraviolet }\end{aligned}$

